\title{
Synthesis and biological evaluation of chemokine receptor ligands with 2-benzazepine scaffold
}

Simone Thum, ${ }^{\text {a }}$ Artur K. Kokornaczyk, ${ }^{\text {a }}$ Tomoaki Seki, ${ }^{\mathrm{b}}$ Monica De Maria, ${ }^{\mathrm{c}, \mathrm{d}}$ Natalia V. Ortiz Zacarias, ${ }^{\mathrm{e}}$ Henk de Vries, ${ }^{\mathrm{e}}$ Christina Weiss, ${ }^{\mathrm{f}}$ Michael Koch, ${ }^{\mathrm{f}}$ Dirk Schepmann, ${ }^{\mathrm{a}}$ Masato Kitamura, ${ }^{\mathrm{b}}$ Nuska Tschammer, ${ }^{\mathrm{g}}$ Laura H. Heitman, ${ }^{\mathrm{e}}$ Anna Junker, ${ }^{\mathrm{a}, \mathrm{h}}$ Bernhard Wünsch ${ }^{\mathrm{a}, \mathrm{h} *}$

a Institut für Pharmazeutische und Medizinische Chemie der Westfälischen Wilhelms-Universität Münster, Corrensstraße 48, D-48149 Münster, Germany

Tel.: +49-251-8333311; Fax: +49-251-8332144; E-mail: wuensch@uni-muenster.de

${ }^{\mathrm{b}}$ Graduate School of Pharmaceutical Sciences, Nagoya University Chikusa, Nagoya 464-8602, Japan

c Department of Chemistry and Pharmacy, Emil Fischer Center, Friedrich Alexander University, Schuhstraße 19, 91052 Erlangen, Germany.

d Department of Developmental Biology, Friedrich Alexander University, Staudtstraße 5, 91058 Erlangen, Germany

e Division of Medicinal Chemistry, Leiden Academic Centre for Drug Research (LACDR), Leiden University, P.O. Box 9502, 2300 RA Leiden, the Netherlands

${ }^{\text {f }}$ Bayer AG, Pharmaceuticals, Drug Discovery - Lead Discovery Wuppertal, Aprather Weg 18a, Gebäude 456, D-42096 Wuppertal, Germany.

g NanoTemper Technologies GmbH, Floessergasse 4, 81369 München

h Cells-in-Motion Cluster of Excellence (EXC 1003 - CiM), Westfälische Wilhelms-Universität Münster, Germany 


\begin{abstract}
Targeting CCR2 and CCR5 receptors is considered as promising concept for the development of novel antiinflammatory drugs. Herein, we present the development of the first probe-dependent positive allosteric modulator (PAM) of CCR5 receptors with a 2-benzazepine scaffold. Compound 14 (2isobutyl- $N$-(\{[N-methyl- $N$-(tetrahydro-2H-pyran-4-yl)amino]methyl $\}$ phenyl)-1-oxo-2,3-dihydro-1H-2benzazepine-4-carboxamide) activates the CCR5 receptor in a CCL4-dependent manner, but does not compete with $\left[{ }^{3} \mathrm{H}\right] \mathrm{TAK}-779$ binding at the CCR5. Furthermore, introduction of a p-tolyl moiety at 7position of the 2-benzazepine scaffold turns the CCR5 PAM 14 into the selective CCR2 receptor antagonist 26b. The structure affinity and activity relationships presented here offer new insights into ligand recognition by CCR2 and CCR5 receptors.
\end{abstract}

\title{
Key words
}

Chemokine receptors; CCR5; CCR2; positive allosteric modulator, 2-benzazepines; TAK-779, TAK652; structure-affinity relationships; structure activity relationships.

\section{Introduction}

Since the first purification and description of the chemoattractant cytokine secreted platelet factor 4 (PF4/CXCL4) in $1977^{1}$ more than 50 human chemokines have been discovered. ${ }^{2}$ Their effects are mediated by 19 G-protein-coupled chemokine receptors. The chemokine receptors CCR2 and CCR5 share $72 \%$ sequence identity (82\% identity in their active sites). ${ }^{3}$ Both receptors play a crucial role in trafficking of immune cells such as macrophages and monocytes, relevant for the development and progression of immunologic and cardiovascular diseases. ${ }^{4}$ The CCR2 receptor is abundantly expressed on blood monocytes and regulates their migration from the bone marrow into inflamed tissue, whereas the CCR5 receptor is expressed on macrophages, T-lymphocytes, and natural killer cells.. ${ }^{5-7}$ CCR2 and 
CCR5 receptors are expressed on different cells, but in a complementary manner. Therefore, dual as well as selective targeting of CCR2 and CCR5 receptors appears to have great potential in the development of novel concepts for the therapy of inflammatory diseases (e.g. atherosclerosis). ${ }^{5}$

The benzo[7]annulene TAK-779 (1) represents one of the first potent non-peptide CCR5 receptor antagonists ( $\mathrm{IC}_{50}=1.4 \mathrm{nM}$, Figure 1). TAK-779 does not only interact with the CCR5 receptor, but also with the CCR2 receptor, although its CCR2 affinity is about 20 -fold lower ( IC $_{50}=27 \mathrm{nM}$ ) compared to its CCR5 affinity. ${ }^{8}$ However, the quaternary ammonium group of TAK-779 leads to very low oral bioavailability. Therefore, very recently we have reported a large structure affinity relationship study with TAK-779 analogs containing a tertiary amine instead of the quaternary ammonium group. Depending on the substitution pattern, potent CCR2 selective and dual CCR2 and CCR5 targeting antagonists were found. ${ }^{9-11}$

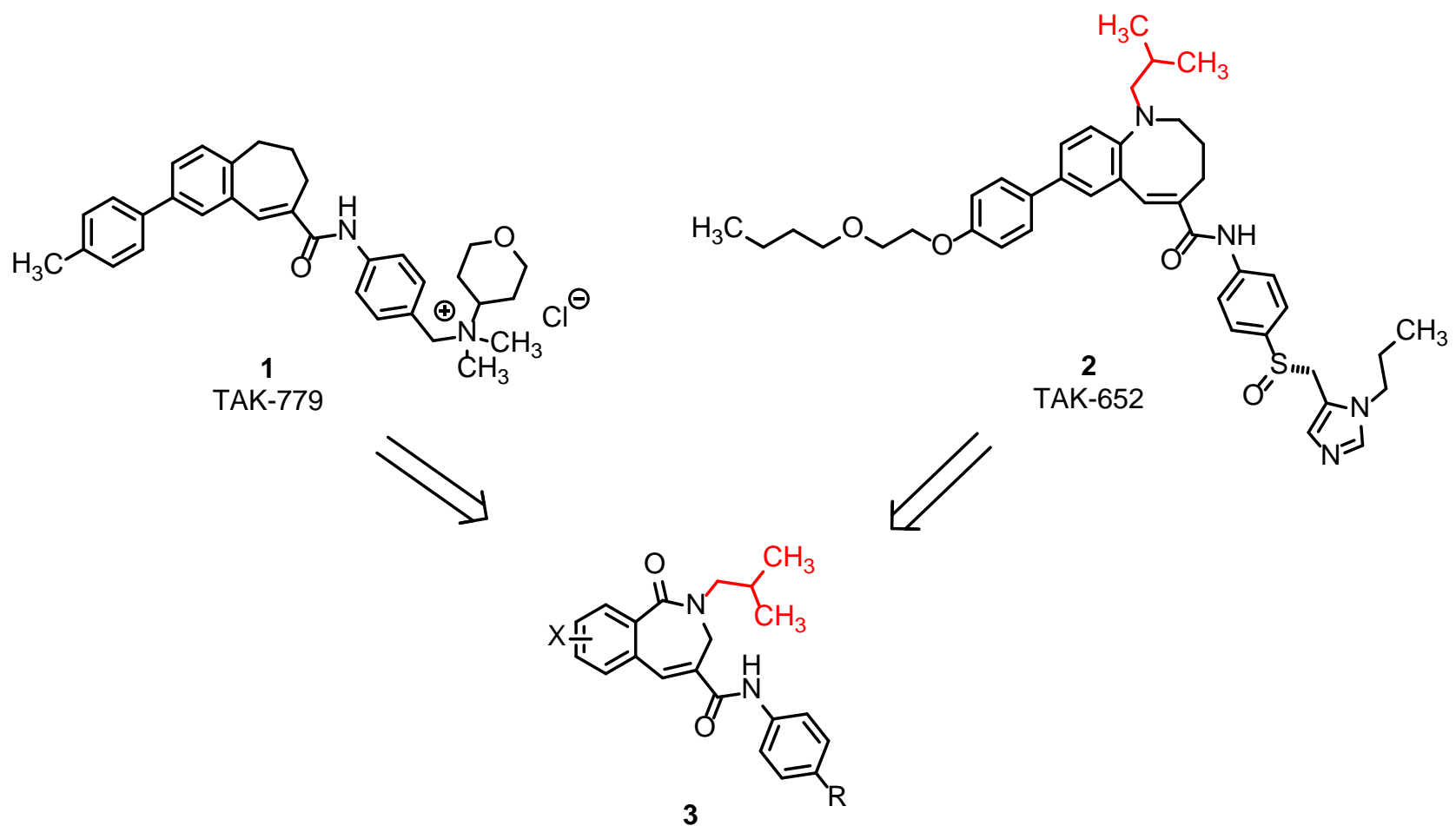

Figure 1: Design of 2-benzazepin-1-ones 3 derived from TAK-779 (1) and TAK-652 (2). 
In addition to TAK-779, the benzazocine TAK-652 (2) served as lead compound in this project (Figure 1). TAK-652 shows high and similar affinities towards CCR5 $\left(\mathrm{IC}_{50}=3.1 \mathrm{nM}\right)$ and CCR2 receptors $\left(\mathrm{IC}_{50}\right.$ = $5.9 \mathrm{nM}$ ), but does not contain a quaternary ammonium group, which had been replaced by a polar sulfoxide. ${ }^{12}$ Structure affinity relationship (SAR) studies performed by Takeda laboratories have shown that reduction of the ring from a benzazocine to a benzazepine did not result in considerable loss of CCR5 affinity. The introduction of an isobutyl side chain onto the benzazocine ring increased CCR5 binding affinity. ${ }^{12}$

Thus, we envisaged to combine the structures of TAK-779 and TAK-652 in 2-benzazepinones 3 . The dihydro-2-benzazepin-1-one system of $\mathbf{3}$ contains a benzannulated seven-membered ring as TAK-779 and an N-heterocycle bearing an isobutyl moiety as TAK-652. The basicity of the amino group in TAK652 (2) is rather low, due to its position at the phenyl ring and due to its conjugation with the amide group at 5-position (phenylogous / vinylogous urea). In the dihydro-2-benzazepin-1-one system 3 the basicity of the N-heterocycle is also negligible (lactam). The position of the lipophilic isobutyl moiety (red) is shifted from 1-position in TAK-652 (2) to 2-position in 3. The selection of substituents X and R was inspired by the substituents of the lead compounds $\mathbf{1}$ and $\mathbf{2}$ and our previous SAR studies. ${ }^{9-11}$ The interaction of the final compounds with CCR2 and CCR5 receptors was evaluated in various biochemical assays.

\section{Results and discussion}

\subsection{Synthesis}

The synthesis of the central building block 11 started with a Michael addition of isobutylamine (5) at methyl acrylate (4) yielding the aminopropanoate 6, which was purified as $\mathrm{HCl}$ salt (Scheme 1). Amine 6 was acylated with commercially available 2-(methoxycarbonyl)benzoic acid (monomethyl phthalate, 
7), which was first converted into its acid chloride using $\mathrm{SOCl}_{2}$. Treatment of the resulting diester $\mathbf{8}$ with $\mathrm{NaH}$ in boiling THF induced the Dieckmann cyclization to produce the cyclic $\beta$-ketoester $\mathbf{9}$. According to the NMR spectra in $\mathrm{CDCl}_{3}$ solution, 9 exists almost exclusively as enol ester as shown in Scheme 1.

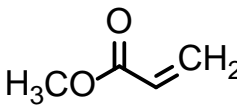<smiles>CC(C)CN</smiles>

5<smiles>COC(=O)CCNCC(C)C</smiles>

$6 \mathrm{HCl}$<smiles>COC(=O)CCN(CC(C)C)C(=O)c1ccccc1C(=O)OC</smiles>

8<smiles>[SiH3]C1[CH]CC1</smiles><smiles>COC(=O)c1c(O)c2ccccc2c(=O)n1CC(C)C</smiles><smiles>COC(=O)C1CN(CC(C)C)C(=O)c2ccccc2C1O</smiles>

10<smiles>COC(=O)C1=Cc2ccccc2C(=O)N(CC(C)C)C1</smiles>

11<smiles>CC(C)CN1CC(C(=O)O)=Cc2ccccc2C1=O</smiles>

12<smiles>CC(C)CN1CC(C(=O)Nc2ccc(CN(C)C3CCOCC3)cc2)=Cc2ccccc2C1=O</smiles>

14

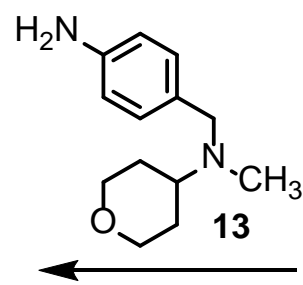

(g)

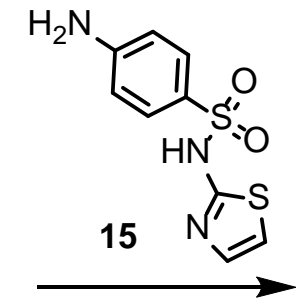

(g)

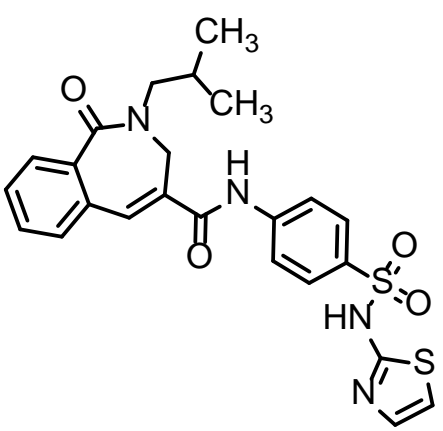

16

Scheme 1: Synthesis of compounds 14 and 16. Reagents and reaction conditions: (a) 1. $\mathrm{NaOCH}_{3}$, $\mathrm{H}_{3} \mathrm{COH}$, rt, 2 h; 2. $\mathrm{HCl} / \mathrm{Et}_{2} \mathrm{O}, 89 \%$. (b) Monomethyl phthalate (7), $\mathrm{SOCl}_{2}$, pyridine; then addition of 6. $\mathrm{HCl}$, pyridine, $\mathrm{CH}_{2} \mathrm{Cl}_{2}$, rt, 4 h, 64\%. (c) $\mathrm{NaH}$, THF, reflux, 3 h, 58\%. (d) $\mathrm{NaBH}_{4}, \mathrm{H}_{3} \mathrm{COH}, 0{ }^{\circ} \mathrm{C}, 1$ h, $58 \%$. (e) $\mathrm{H}_{3} \mathrm{CSO}_{2} \mathrm{Cl}, \mathrm{NEt}_{3}, \mathrm{DBU}, \mathrm{CH}_{2} \mathrm{Cl}_{2}$, rt, 12 h, 76\%. (f) $5 \mathrm{M} \mathrm{NaOH}, \mathrm{H}_{3} \mathrm{COH}$, reflux, 40 min, $100 \%$. (g) $\mathrm{NEt}_{3}$ (2 equiv.), HATU (1.1 equiv.), THF, rt, 12 h, 14: 48\%, 16: 8\%. 
Reduction of the enol ester $\mathbf{9}$ with $\mathrm{NaBH}_{4}$ in $\mathrm{H}_{3} \mathrm{COH}$ afforded two diastereomeric $\beta$-hydroxy esters 10. Since in the next step both diastereomers of $\mathbf{1 0}$ form the same $\alpha, \beta$-unsaturated ester 11, the diastereomeric $\beta$-hydroxy esters $\mathbf{1 0}$ were not separated. Elimination of $\mathrm{H}_{2} \mathrm{O}$ was performed upon treatment of $\beta$-hydroxy esters $\mathbf{1 0}$ with methanesulfonyl chloride in the presence of NEt3. Subsequent addition of DBU induced the $\beta$-elimination of the intermediate methanesulfonate to give the $\alpha, \beta$ unsaturated ester $\mathbf{1 1}$ in 76\% yield. Saponification of methyl ester $\mathbf{1 1}$ with $\mathrm{NaOH}$ provided the acid $\mathbf{1 2}$ in almost quantitative yield.

The acid 12 was used to prepare secondary amides 14 and 16, which have similar structures as the lead compounds 1 and 2. For the amide coupling the uronium salt $O$-(7-azabenzotriazol-1-yl)- $N, N, N^{\prime}, N^{\prime}-$ tetramethyluronium hexafluorophosphate (HATU) was used. Whereas coupling of acid 12 with the primary amine $\mathbf{1 3}$ provided the secondary amide $\mathbf{1 4}$ in $48 \%$ yield, the corresponding coupling with sulfathiazole (15) gave only 8\% of secondary amide $\mathbf{1 6 .}$

In the BRET-based cAMP assay, TAK-779-derived secondary amide $\mathbf{1 4}$ showed a CCL4-dependent positive allosteric modulation (PAM) of CCR5 receptor (see part 3, Biological activity), whereas the sulfonamide derivative $\mathbf{1 6}$ was inactive, indicating the requirement of a basic benzylamine moiety for CCR5 receptor binding. This promising result stimulated further exploration of the substitution pattern of compound 14. At first, a bromine atom should be introduced into the benzene moiety of the 2benzazepine ring of the key compound 11, since bromoarenes could be used for the introduction of a broad variety of diverse substituents by Pd-catalyzed cross-coupling reactions. Unfortunately, all attempts to brominate $\mathbf{1 1}$ using $\mathrm{Br}_{2}$ or NBS under different reaction conditions led to loss of the double bond of the $\alpha, \beta$ unsaturated ester indicating higher reactivity of the double bond compared to the benzene ring. 
Therefore, it was planned to change the synthetic strategy and introduce the Br-atom at a very early stage of the synthesis. For this purpose, phthalic anhydride (17) was treated with an aqueous solution of $\mathrm{NaOH}$ and $\mathrm{Br}_{2}$ which provided 4-bromophthalic acid (18) ${ }^{13}$ in $95 \%$ yield (Scheme 2). Treatment of diacid 18 with methanol in the presence of TMSCl provided a 1:1 mixture of regioisomeric monomethyl esters 19a and 19b in $94 \%$ yield. The further synthetic route to obtain esters 23 is very similar to the synthesis of ester 11. Activation of the mono acids 19a,b with $\mathrm{SOCl}_{2}$ and subsequent reaction of the acid chlorides with aminopropanoate 6 led to the amides 20, which underwent Dieckmann condensation to afford the enol esters 21a,b. $\mathrm{NaBH}_{4}$ reduction of 21a,b provided the $\beta$-hydroxyesters 22a,b, which reacted with mesyl chloride and DBU to yield the $\alpha, \beta$-unsaturated esters 23a,b. In the next step the $p$ tolyl moiety of the lead compound TAK-779 (1) should be introduced. Suzuki-Miyaura cross-coupling of the regioisomeric bromo derivatives 23a,b with 4-methylbenzeneboronic acid and $\mathrm{PdCl}_{2}(\mathrm{dppf})$ as catalyst provided the regioisomeric p-tolyl derivatives 24a,b. Saponification of the esters 24a,b with $\mathrm{NaOH}$ led to acids 25a,b, which were coupled with amine $\mathbf{1 3}$ to afford the final amides 26a,b (Scheme 2). 


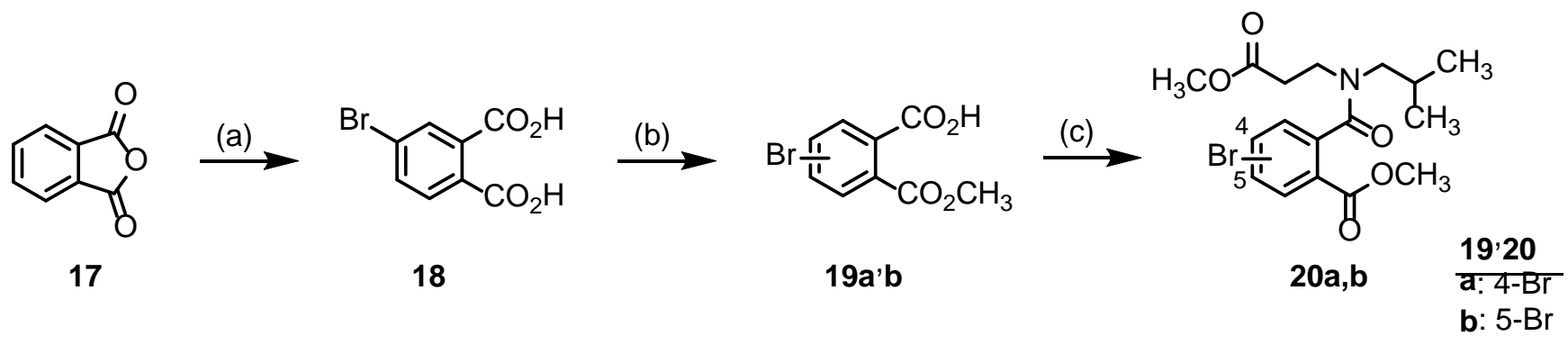<smiles></smiles>

21a,b

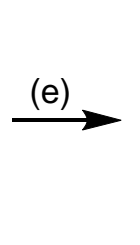<smiles>COC(=O)C1CN(CC(C)C)C(=O)c2cc(Br)ccc2C1O</smiles>

22a,b<smiles>COC(=O)C1=CC2=C[In](Br)C=C2C(=O)N(CC(C)C)C1</smiles>

23a,b
$21^{-} 23$

a: $8-\mathrm{Br}$

b: $7-\mathrm{Br}$

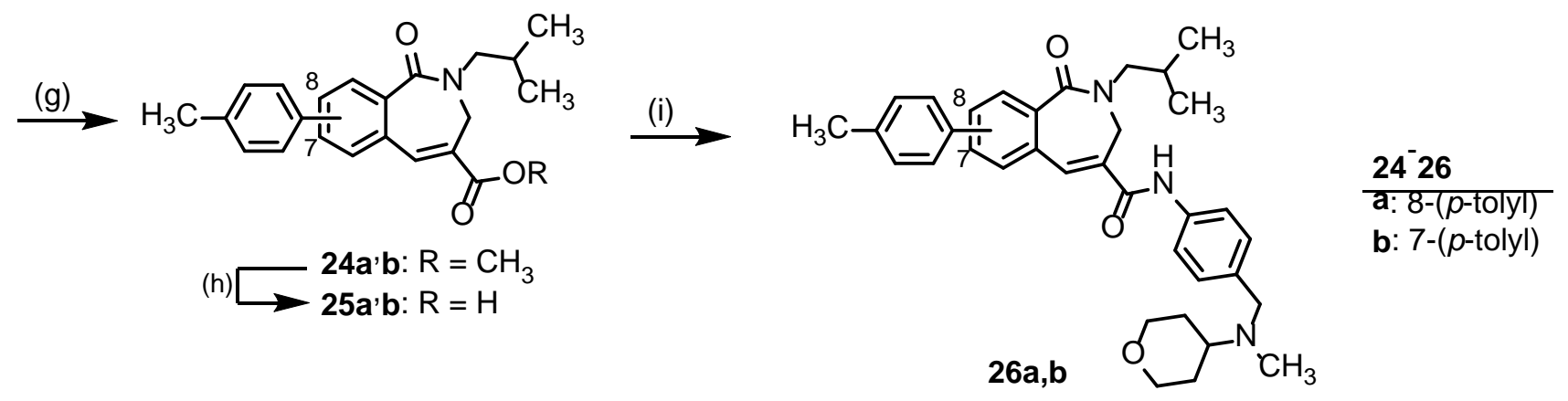

Scheme 2: Synthesis of 7- and 8-(p-tolyl)-2-benzazepine-4-carboxamides 26a,b. Reagents and reaction conditions: (a) $\mathrm{Br}_{2}, \mathrm{NaOH}, \mathrm{H}_{2} \mathrm{O}$, reflux, 72 h, 95\%. (b) TMSCl, $\mathrm{H}_{3} \mathrm{COH}, \mathrm{rt}, 12$ h, 94\%. (c) 1. $\mathrm{SOCl}_{2}$, pyridine; 2. 6. $\mathrm{HCl}$, pyridine, $\mathrm{CH}_{2} \mathrm{Cl}_{2}$, rt, 4 h, 64\%. (d) $\mathrm{NaH}$, THF, reflux, 3 h, 21a: 36\%, 21b: 38\%. (e) $\mathrm{NaBH}_{4}, \mathrm{H}_{3} \mathrm{COH}, 0^{\circ} \mathrm{C}, 1$ h, 22a: 58\%, 22b: 45\%. (f) $\mathrm{H}_{3} \mathrm{CSO}_{2} \mathrm{Cl}, \mathrm{NEt}_{3}, \mathrm{DBU}, \mathrm{CH}_{2} \mathrm{Cl}_{2}, \mathrm{rt}, 12$ h, 23a: 74\%, 23b: 84\%. (g) 4-Methylbenzeneboronic acid, $\mathrm{PdCl}_{2}$ (dppf) (5 mol\%), KOAc, DME, reflux, 12 h, 24a: 50\%, 24b: 58\%. (h) $5 \mathrm{M} \mathrm{NaOH}, \mathrm{H}_{3} \mathrm{COH}$, reflux, 30 min, 97\%. (i) 13, HATU, NEt 3 , THF, rt, 12 h, 26a: 39\%, 26b: 34\%.

The separation of the regioisomers a and $\mathbf{b}$ was performed at various stages at the synthesis. Separation at the very early stage of enol esters $\mathbf{2 1}$ and performing the synthesis with pure regioisomers 21a and 21b gave clear spectra of all intermediates. An X-ray crystal structure of the 7-bromo derivative 21b proved the existence of the $\beta$-ketoester in the enol tautomer and the position of the $\mathrm{Br}$-atom. ${ }^{14}$ 
Separation of the intermediate $\alpha, \beta$-unsaturated esters 23a and 23b gave higher yields than the early separation of 21a and 21b. However, separation of the final $p$-tolyl derivatives $\mathbf{2 6 a}$ and $\mathbf{2 6 \mathbf { b }}$ turned out to be the most efficient strategy, since the corresponding transformations and purifications had to be performed only once for the mixture of regioisomers, respectively. However, preparative HPLC had to be used for the separation of $\mathbf{2 6 a}$ and $\mathbf{2 6 \mathbf { b }}$ and the NMR spectra of all intermediates showed two sets of signals.

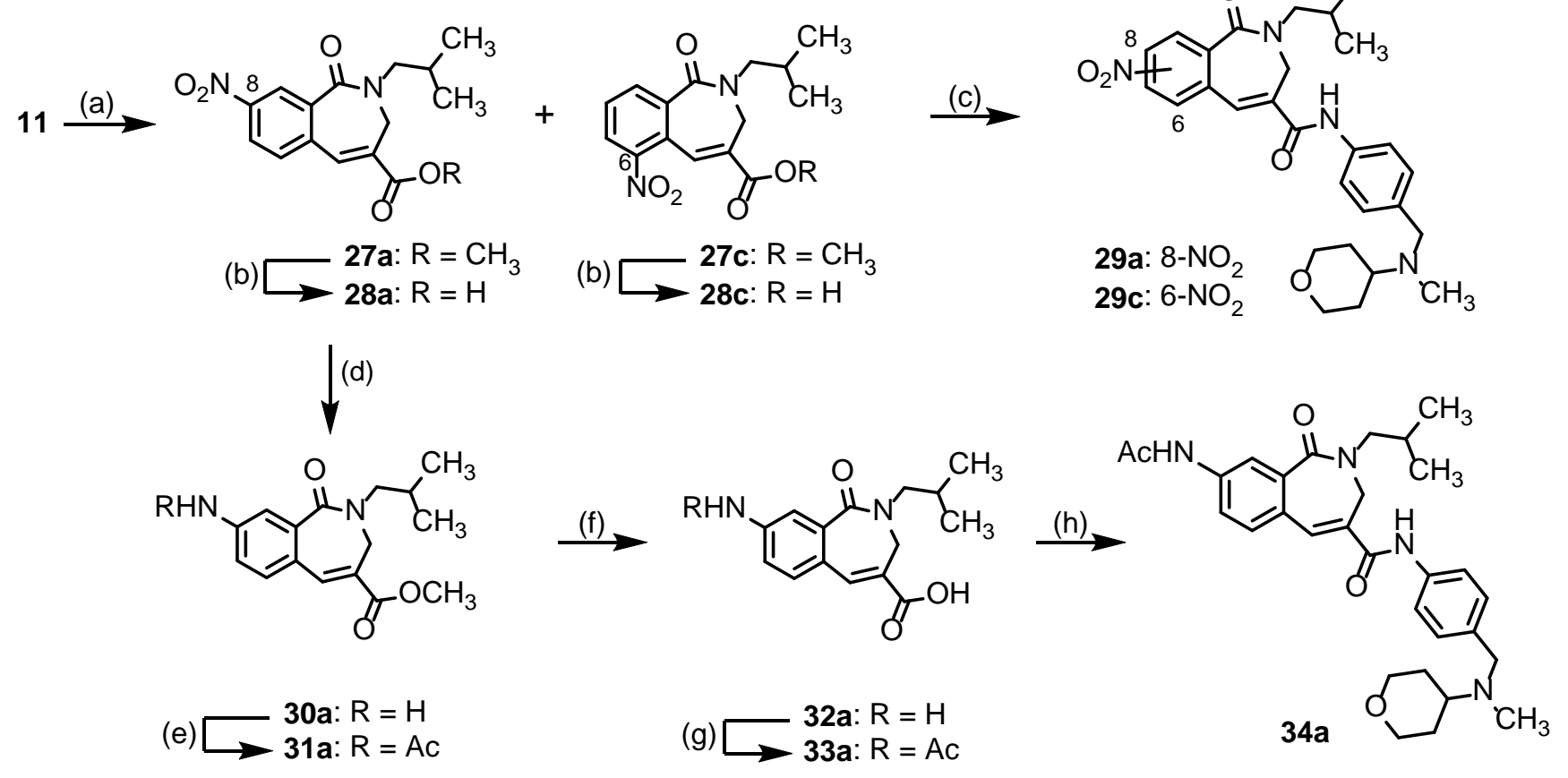

Scheme 3: Synthesis of $\mathrm{NO}_{2}$ derivatives 29 and acetamide 34a. Reagents and reaction conditions: (a) $\mathrm{HNO}_{3}$ (100\%), $\mathrm{H}_{2} \mathrm{SO}_{4}$ (95 - 97\%), $\mathrm{CH}_{3} \mathrm{NO}_{2}$, rt, 2 h, 83\%. (b) $5 \mathrm{M} \mathrm{NaOH}, \mathrm{H}_{3} \mathrm{COH}$, reflux, 97\%. (c) 13, HATU, NEt 3 , THF, rt, 12 h, 29a: 9\%, 29c: 14\%. (d) Fe, conc. HCl, EtOH, reflux, 2 h, 75\%. (e) $\mathrm{Ac}_{2} \mathrm{O}, \mathrm{NEt}_{3}, \mathrm{CH}_{2} \mathrm{Cl}_{2}, 6$ h, rt, 59\%. (f) $\mathrm{NaOH}, \mathrm{H}_{3} \mathrm{COH}, 10$ min, rt. (g) $\mathrm{Ac}_{2} \mathrm{O}, \mathrm{NEt}_{3}, \mathrm{CH}_{2} \mathrm{Cl}_{2}, 6$ h, rt, $69 \%$. (h) 13, HATU, NEt 3 , THF, rt, 12 h, 47\%.

In addition to the $p$-tolyl moiety, the introduction of electron withdrawing $\mathrm{NO}_{2}$ group was envisaged, which could be converted into various other functional groups, subsequently. For this purpose, the naked $\alpha, \beta$-unsaturated ester 11 was reacted with $\mathrm{HNO}_{3} / \mathrm{H}_{2} \mathrm{SO}_{4}$ to obtain a mixture of regioisomeric 8- $\mathrm{NO}_{2}$ - and 
6- $\mathrm{NO}_{2}$-2-benzazepines 27a and 27c in the ratio 7:3 in 97\% yield (Scheme 3). After chromatographic separation of the regioisomeric esters 27a and 27c, saponification with $\mathrm{NaOH}$ led to the acids $\mathbf{2 8 a}$ and 28c, which were coupled with the amine 13 to afford the final amides 29a and 29c.

The main regioisomer 27a was reduced with Fe in the presence of $\mathrm{HCl}$ to provide the primary amine 30a, which was acylated with $\mathrm{Ac}_{2} \mathrm{O}$ to give the acetamide 31a (Scheme 3). In the next step, the ester 31a was treated with $\mathrm{NaOH}$. Unexpectedly, not only the ester moiety but also the acetamide group was hydrolyzed to produce the amino acid 32a. Therefore, the amino moiety was acetylated once more with $\mathrm{Ac}_{2} \mathrm{O}$, before the final HATU-coupling of the acid 33a with amine $\mathbf{1 3}$ was performed to produce the desired acetamide 34a.
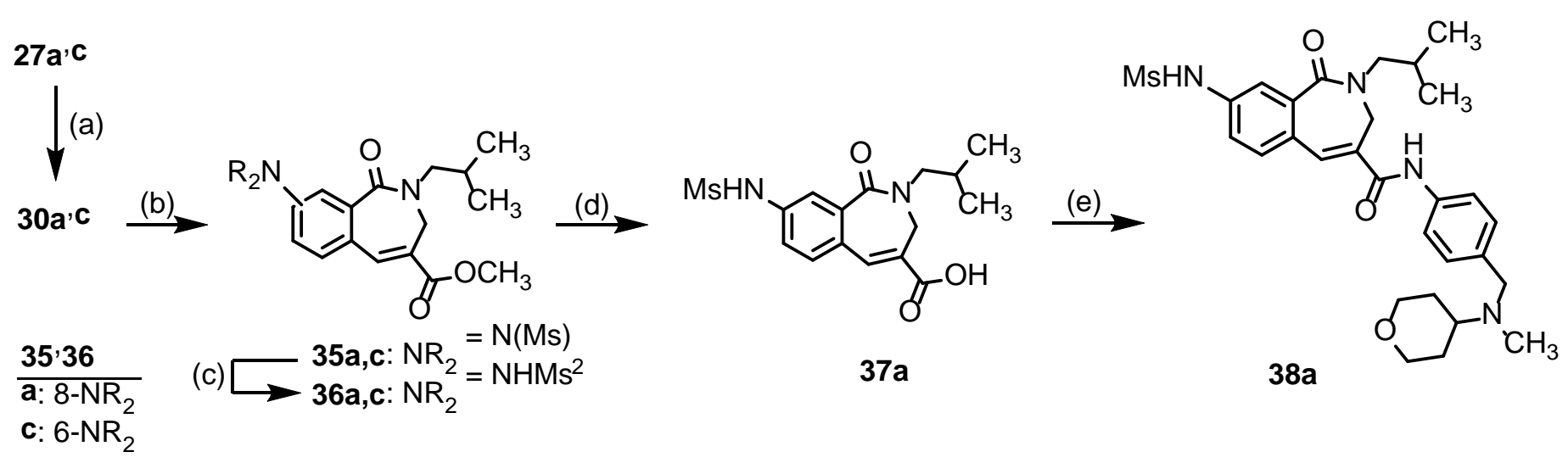

Scheme 4: Synthesis of sulfonamide 38a: Reagents and reaction conditions: (a) Fe, conc. HCl, EtOH, reflux, $2 \mathrm{~h}, 74 \%$. (b) $\mathrm{CH}_{3} \mathrm{SO}_{2} \mathrm{Cl}$ (1 equiv.), $\mathrm{NEt}_{3}, \mathrm{CH}_{2} \mathrm{Cl}_{2}, 3 \mathrm{~d}$, then 4 x 0.3 equiv. $\mathrm{CH}_{3} \mathrm{SO}_{2} \mathrm{Cl}_{\text {and }} \mathrm{NEt}_{3}$ every 6 h, rt, 91\%. (c) $\mathrm{NaOH}, \mathrm{H}_{3} \mathrm{COH}, 20$ min, rt, 43\%. (d) $\mathrm{LiOH}$ (4 equiv.), $\mathrm{H}_{3} \mathrm{COH}, 3 \mathrm{~h}$ rt, 1 h $50{ }^{\circ} \mathrm{C}$, 53\%. (e) 13, HATU, NEt3, THF, rt, 12 h, 20\%.

Reduction of the regioisomers $\mathrm{NO}_{2}$-derivatives 27a,c with $\mathrm{Fe}$ and conc. $\mathrm{HCl}$ provided a mixture of regioisomeric primary amines 30a,c, which was treated with methanesulfonyl chloride in the presence of triethylamine. Although only one equivalent of methanesulfonyl chloride was added, considerable 
amounts of disulfonamides 35a,c were formed. Therefore, an excess of methanesulfonyl chloride was used to obtain the disulfonamides 35a,c in 91\% yield. Subsequent hydrolysis of the disulfonamides 35a,c with $\mathrm{NaOH}$ in methanol produced the monosulfonamides 36a,c. Finally, the ester moiety of 36a,c was hydrolyzed with $\mathrm{LiOH}$. Chromatographic purification of the resulting acids provided the main regioisomer 37a in 53\% yield, which was coupled with the amine $\mathbf{1 3}$ to afford the amide $\mathbf{3 8 a}$ in $20 \%$ yield (Scheme 4).

\subsection{Biological activity}

The interaction of sulfathiazole coupled amide $\mathbf{1 6}$ as well as 2-benzazepine-4-carboxamides 14, 26, 29, 34, and 38 bearing different substituents in 8- (a-series), 7- (b-series) and 6-position (c-series) with CCR2 and CCR5 receptors was tested in various CCR2 and CCR5 assays.

In the first assay, the test compounds competed with the radioligand $\left[{ }^{3} \mathrm{H}\right] \mathrm{INCB} 3344$ for CCR2 receptor binding on membrane preparations from U2OS cells stably expressing CCR2. With exception of the 7p-tolyl derivative $\mathbf{2 6 b}$, the test compounds did not reduce the specific binding of the radioligand $\left[{ }^{3} \mathrm{H}\right] \mathrm{INCB} 3344$ to a large extent at a concentration of $1 \mu \mathrm{M}$ indicating rather low CCR2 affinity (Table 1). Only the 7-p-tolyl derivative $\mathbf{2 6 b}$ displayed a moderate CCR2 affinity with an $\mathrm{IC}_{50}$ value of $387 \mathrm{nM}$.

In addition to binding, the antagonistic activity of the test compounds at the CCR2 receptor was determined in a $\mathrm{Ca}^{2+}$ flux assay employing the Chem-1 cell line stably transfected with the human

CCR2b receptor. Influx of $\mathrm{Ca}^{2+}$ ions was induced by recombinant human CCL2 (MCP-1). The inhibition of this $\mathrm{Ca}^{2+}$ influx by the test compounds was recorded. Table 1 shows that only the $p$-tolyl derivatives 26 were able to inhibit the $\mathrm{Ca}^{2+}$ influx. Whereas the 8-p-tolyl derivative 26a revealed only very low inhibition, a significant inhibition was observed for the regioisomer $\mathbf{2 6 \mathbf { b }}$. This result is explained by the 
structural relationship of $\mathbf{2 6 \mathbf { b }}$ and the lead compound TAK-779. However, the $\mathrm{IC}_{50}$ value of $140 \mathrm{nM}$ is considerably higher than the $\mathrm{IC}_{50}$ value of TAK-779. The inhibition of the $\mathrm{Ca}^{2+}$ flux induced by the 7-ptolyl derivative $\mathbf{2 6 b}$ correlates nicely with its moderate CCR2 binding affinity.

Table 1: Receptor affinities and activities at CCR2 and CCR5 receptors.
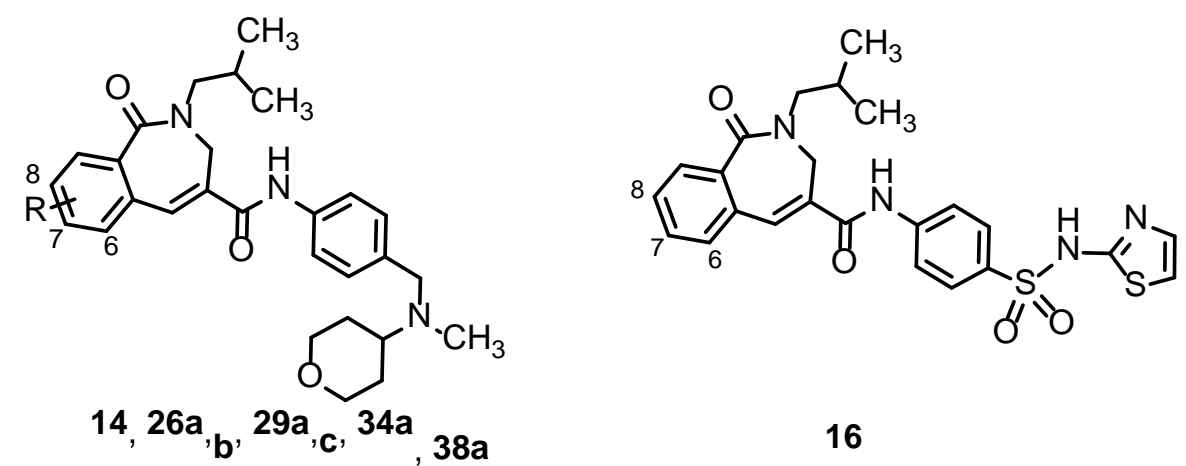

16

\begin{tabular}{|c|c|c|c|c|c|}
\hline \multirow[b]{2}{*}{ Compd. } & \multirow[b]{2}{*}{$\mathrm{R}$} & \multicolumn{2}{|c|}{ CCR2 } & \multicolumn{2}{|c|}{ CCR5 } \\
\hline & & $\begin{array}{c}\left.{ }^{3} \mathrm{H}\right] \mathrm{INCB} 3344 \\
\text { displacement } \\
\mathrm{IC}_{50}(\mathrm{nM})^{[\mathrm{a}]}\end{array}$ & $\begin{array}{c}\mathrm{Ca}^{2+} \text { flux } \\
\mathrm{IC}_{50}(\mathrm{nM})^{[\mathrm{b}]}\end{array}$ & $\begin{array}{c}{\left[{ }^{3} \mathrm{H}\right] \mathrm{TAK}-779} \\
\text { displacement } \\
\mathrm{IC}_{50}[\mathrm{nM}]^{[\mathrm{c}]}\end{array}$ & $\begin{array}{l}\text { cAMP-BRET } \\
(\text { CCL4) } \\
\text { EC }_{50}(\mathrm{nM})^{[\mathrm{d}]}\end{array}$ \\
\hline 14 & $\mathrm{H}$ & $18 \%$ & n.d. & $0 \%$ & 2470 \\
\hline 16 & $\mathrm{H}$ & $18 \%$ & n.d. & $0 \%$ & $>10$ \\
\hline $26 a$ & 8-p-tolyl & $0 \%$ & 3000 & $0 \%$ & $>10$ \\
\hline $26 b$ & 7-p-tolyl & 387 & 140 & $0 \%$ & $>10$ \\
\hline $29 a$ & $8-\mathrm{NO}_{2}$ & $9 \%$ & n.d. & $0 \%$ & $>10$ \\
\hline $29 c$ & $6-\mathrm{NO}_{2}$ & $6 \%$ & n.d. & $0 \%$ & $>10$ \\
\hline $34 a$ & 8-NHAc & $15 \%$ & n.d. & $0 \%$ & $>10$ \\
\hline $38 a$ & $8-\mathrm{NHSO}_{2} \mathrm{CH}_{3}$ & $18 \%$ & n.d. & $0 \%$ & $>10$ \\
\hline TAK-779 & - & 50 & 0.95 & 2 & 7 \\
\hline
\end{tabular}

[\%] inhibition at a test compound concentration of $1 \mu \mathrm{M}(\mathrm{n}=3)$. n.d. not determined.

[a] Displacement of the radioligand $\left[{ }^{3} \mathrm{H}\right] \mathrm{INCB} 3344$ at a concentration of $1 \mu \mathrm{M}$ of the test compound $(\mathrm{n}=3)$.

[b] Inhibition of $\mathrm{Ca}^{2+}$ mobilization after activation by $5 \mathrm{nM}$ MCP-1 $(\mathrm{n}=3)$.

[c] Displacement of the radioligand $\left[{ }^{3} \mathrm{H}\right] \mathrm{TAK}-779$ at a concentration of $1 \mu \mathrm{M}$ of the test 
compound ( $\mathrm{n}=3)$.

[d] Stimulation of cAMP production after inhibition with 0.2 nM CCL4 (n = 3).

For investigation of the interaction of the test compounds with CCR5 receptors, a binding assay was performed at first. In this assay the radioligand $\left[{ }^{3} \mathrm{H}\right] \mathrm{TAK}-779$ was used as competitor and commercially available membrane preparations containing high amounts of CCR5 receptors were employed as source of receptors. At a concentration of $1 \mu \mathrm{M}$ the test compounds could not displace the specific radioligand binding (Table 1). In particular, the low CCR5 interaction of the p-tolyl derivative 26b was unexpected, as this compound is structurally very similar to the lead compound TAK-779. To address the surprising lack of CCR5 affinity of compound $\mathbf{2 6 b}$, the central core structures of $\mathbf{2 6 \mathbf { b }}$ (B) and TAK-779 (A) were compared via flexible alignment. In Figure 2, part I the superposition of the core structures demonstrates different angles within the 7-membered rings of TAK-779 (1) and 2-benzazepinone 26b. The different

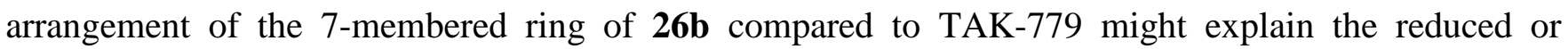
eliminated CCR5 affinity of 26b. Obviously, the CCR5 receptor does not tolerate the introduction of the $\mathrm{N}$-isobutyl substituted amide moiety within the seven-membered part of the ring system. On the other hand, an alignment of the core structures of $\mathbf{2 6 b}$ (B) and TAK-652 (C) (Figure 2, part II) reveals a very similar positioning of the isobutyl chain that might explain the moderate CCR2 binding affinity and activity.

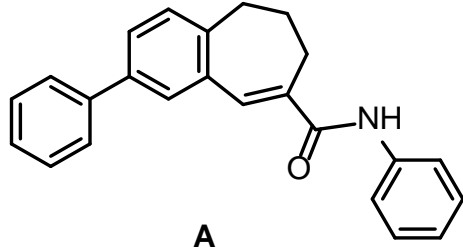

blue<smiles>[R]OC1=Cc2cc(-c3ccccc3)ccc2C(=O)N(CC(C)C)C1</smiles>

pink

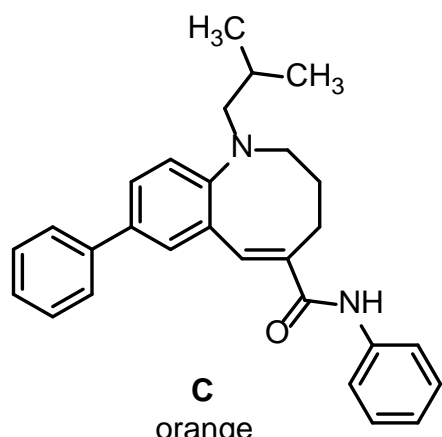

orange 

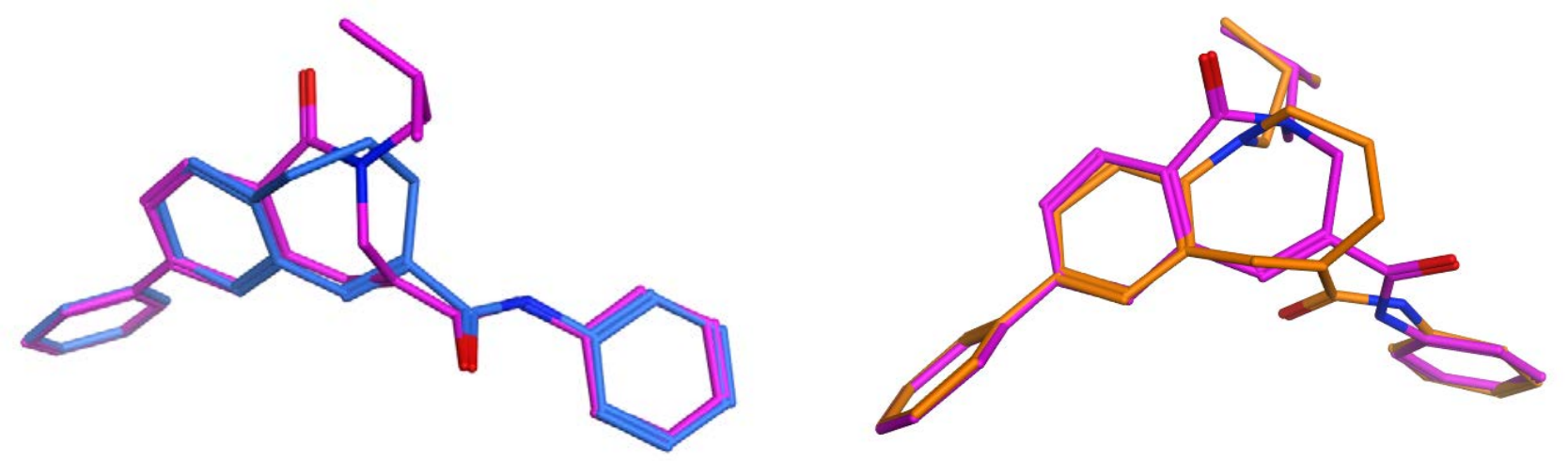

Figure 2: I) Alignment of central core structures of TAK-779 (A, blue) with 7-p-tolyl derivative 26b (B, pink). II) Alignment of central core structures of TAK-652 (C, orange) with 7-p-tolyl derivative 26b (B, pink).

To assess the effect of compounds on the CCL4 or CCL5-induced $\mathrm{G}_{i}$ protein-dependent signaling of CCR5, we monitored the changes in cAMP levels by use of the bioluminescence resonance energy transfer- (BRET-) based cAMP sensor CAMYEL. This biosensor is comprised of a catalytically inactive Epac1 that is fused to Citrine at its N-terminus and to Renilla reniformis luciferase (Rluc) at the Cterminus. ${ }^{15}$ For these experiments, HEK293T cells were transiently transfected with the human CCR5 receptor and the CAMYEL biosensor. The accumulation of cAMP was induced by forskolin. TAK-779 (1) was used as reference inhibitor of CCL4 and CCL5 action. 


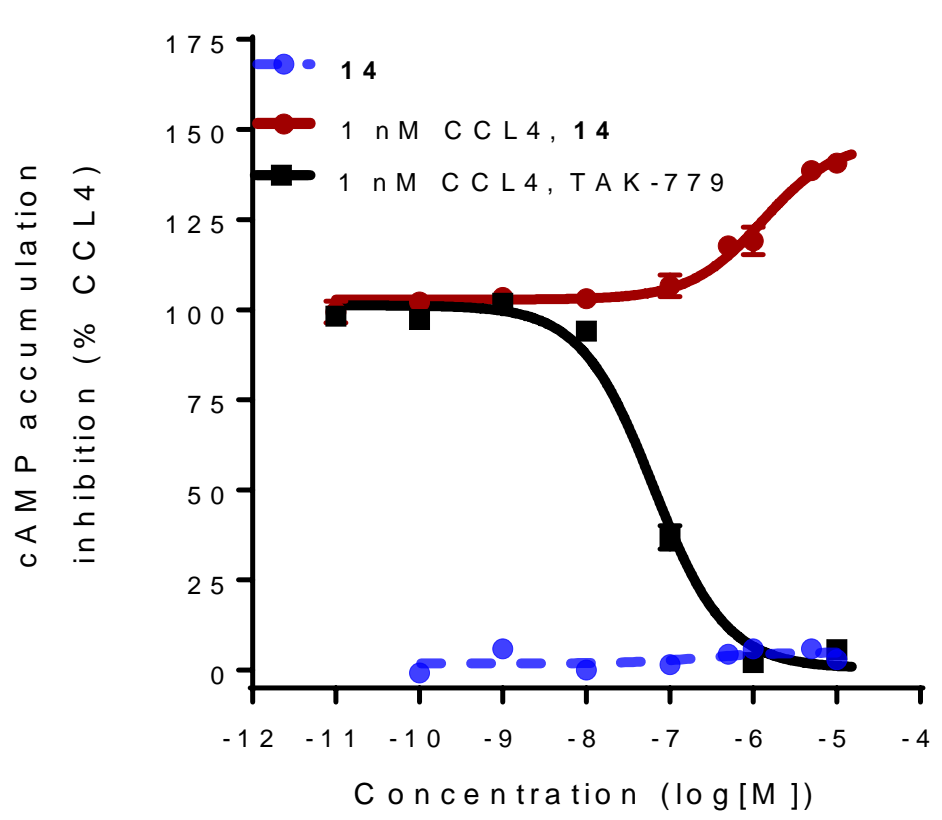

Figure 3: The BRET-based cAMP assay for compounds 14 and TAK-779 (1) with CCL4 at the CCR5 receptor.

In the cAMP assay only the unsubstituted 2-benzazepinone $\mathbf{1 4}$ displayed remarkable biological effects. This compound showed clear probe-dependence at the CCR5 receptor. Although that compound $\mathbf{1 4}$ itself had no intrinsic agonist activity (Figure 3), it behaved as positive allosteric modulator (PAM) when CCL4 was used to activate the CCR5 receptor ( $\mathrm{IC}_{50}=2.47 \mu \mathrm{M}$, Table 1 , Figure 3 ). At the same time, the compound $\mathbf{1 4}$ was fully inactive in the presence of CCL5. This CCL4-dependence indicates a slightly different CCR5 receptor binding pocket for compound 26b compared to TAK-779, since TAK779 displays a negative allosteric modulation with both chemokines CCL4 and CCL5. Of note, probedependent negative allosteric modulators (NAM) of CXCR3 receptors were recently reported. ${ }^{16,17}$ Probe-dependent allosteric modulation provides a promising strategy for fine tuning of the chemokine response and corresponding ligands are therefore of great interest for drug development in the chemokine receptor field. If we consider that $\mathbf{1 4}$ binds to a different subpocket than TAK-779, the lack of CCR5 affinity of $\mathbf{1 4}$ in a radioligand binding assay is not surprising, as it would not compete with 
$\left[{ }^{3} \mathrm{H}\right] \mathrm{TAK}-779$. In the benzene ring of the sulfathiazole-derived amide $\mathbf{1 6}$ further substituents are also missing. However, 16 does not induce similar effects as $\mathbf{1 4}$, which is probably due to the lacking basic amino moiety.

\section{Conclusion}

The introduction of the $p$-tolyl group at 7-position of the 2-benzazepine scaffold seems to be crucial for CCR2 receptor interactions. In the CCR2 binding assay and the $\mathrm{Ca}^{2+}$ flux assay, the 7-p-tolyl derivative 26b displayed moderate affinity $\left(\mathrm{IC}_{50}=387 \mathrm{nM}\right)$ and activity $\left(\mathrm{IC}_{50}=140 \mathrm{nM}\right)$. Obviously the CCR2 receptor is able to accommodate at the different structure of the 2-benzazepinone $\mathbf{2 6 \mathbf { b }}$ compared to the structures of the lead compounds TAK-779 and TAK-652. Despite the different conformations of the scaffolds, the isobutyl moieties of TAK-652 and $\mathbf{2 6 \mathbf { b }}$ adopt similar orientations, which might explain the moderate interactions of $\mathbf{2 6 \mathbf { b }}$ with the CCR2 receptor. The corresponding 8-p-tolyl regioisomer 26a was approx. 20-fold less potent in both assays, other substituents at the 2-benzazepine framework were not tolerated by the CCR2 receptor.

The synthesized 2-benzazepinones did not show any affinity towards the CCR5 receptor in the $\left[{ }^{3} \mathrm{H}\right] \mathrm{TAK}-779$ competition assay. Despite the absence of TAK-779 displacement at CCR5 receptors, the naked 2-benzazepinone $\mathbf{1 4}$ led to an increased production of cAMP after stimulation of the CCR5 receptor with CCL4. This probe-dependent positive allosteric modulation of the CCR5 receptor, which was not observed after stimulation with CCL5, was unexpected. 


\section{Experimental Part}

\subsection{General}

Unless otherwise noted, moisture sensitive reactions were conducted under dry nitrogen. THF was dried with sodium/benzophenone, $\mathrm{CH}_{2} \mathrm{Cl}_{2}$ with calcium hydride and both were freshly distilled before use. Thin layer chromatography (tlc): Silica gel $60 \mathrm{~F}_{254}$ plates (Merck). Flash chromatography (fc): Silica gel 60, 40-64 $\mu \mathrm{m}$ (Merck); parentheses include: diameter of the column, length of column, fraction size, eluent, $\mathrm{R}_{\mathrm{f}}$ value. Melting point: melting point system MP50 (Mettler Toledo), uncorrected. IR: IR spectrophotometer 480Plus FT-ATR-IR (Jasco). ${ }^{1} \mathrm{H}$ NMR (400 MHz), ${ }^{13} \mathrm{C}$ NMR (100 MHz): Mercury plus 400 spectrometer (Varian); $\delta$ in ppm related to tetramethylsilane; coupling constants are given with

$0.5 \mathrm{~Hz}$ resolution. MS: APCI = atmospheric pressure chemical ionization: MicroTOFQII (Bruker Daltonics), ESI = electro spray ionization: MicroTof (Bruker Daltonics, Bremen), calibration with sodium formate clusters before measurement. Deviations of the found exact masses from the calculated exact masses were $5 \mathrm{mDa}$ or less, unless otherwise stated. The data were analyzed with DataAnalysis (Bruker).

\subsection{HPLC methods}

\subsubsection{Method 1: Purity of compounds}

Merck Hitachi equipment; UV detector: L-7400; autosampler: L-7200; pump: L-7100; degasser: L-7614; Method A: column: LiChrospher ${ }^{\circledR} 60$ RP-select B (5 $\left.\mu \mathrm{m}\right), 250-4$ mm cartridge; flow rate: 1.00 $\mathrm{mL} / \mathrm{min}$; injection volume: $5.0 \mu \mathrm{L}$; detection $\lambda=210 \mathrm{~nm}$; solvents: A: water with $0.05 \%(\mathrm{v} / \mathrm{v})$ trifluoroacetic acid; B: acetonitrile with $0.05 \%(\mathrm{v} / \mathrm{v})$ trifluoroacetic acid: gradient elution: (A \%): 0-4 min: $90 \%$, 4-29 min: gradient from $90 \%$ to $0 \%$, 29-31 min: $0 \%, 31-31.5$ min: gradient from $0 \%$ to $90 \%$, 31.5-40 min: 90\%. 


\subsubsection{Method 2: Preparative HPLC}

Merck Hitachi equipment; UV detector: L-7400; autosampler: L-7200; pump: L-7100; interface: D7000; data acquisition: HSM Software (LaChrom, Merck-Hitachi); solvent: acetonitrile : $\mathrm{H}_{2} \mathrm{O}$ 70:30; column: Phenomenex ${ }^{\circledR}$ Gemini $5 \mu \mathrm{m}$ C18 110A, 250 - 21.2 mm; flow rate: $10.00 \mathrm{~mL} / \mathrm{min}$; injection volume $500.0 \mu \mathrm{L}$; detection: wavelength: $254 \mathrm{~nm}$, stop time: $60.0 \mathrm{~min}$.

\subsection{Synthetic procedures}

\subsubsection{Methyl 3-(isobutylamino)propanoate $(6 \bullet \mathrm{HCl})$}

Methyl 4-acrylate (9.81 g, $114 \mathrm{mmol}, 15.0 \mathrm{~mL}$ ) was added slowly to a vigorously stirred mixture of isobutylamine (10 g, $137 \mathrm{mmol}, 13.6 \mathrm{~mL})$ and sodium methanolate (123 mg, $2.28 \mathrm{mmol}$ ) in methanol (70 mL). The mixture was stirred for $2 \mathrm{~h}$ at rt, concentrated in vacuo and the residue was purified by fc $\left(\varnothing=4 \mathrm{~cm}, \mathrm{~h}=16 \mathrm{~cm}\right.$, cyclohexane $/$ ethyl acetate $=1: 2+1 \%$ triethylamine, $\left.\mathrm{R}_{\mathrm{f}}=0.71\right)$ to give a colorless oil. The oil was dissolved in $\mathrm{Et}_{2} \mathrm{O}$ and $2 \mathrm{M} \mathrm{HCl}$ in $\mathrm{Et}_{2} \mathrm{O}$ was added to the solution. A colorless precipitate was formed, which was separated by filtration with $\mathrm{Et}_{2} \mathrm{O}$ to give $\mathbf{6}$ as a $\mathrm{HCl}$-salt. Colorless solid, mp $187^{\circ} \mathrm{C}$, yield $23.8 \mathrm{~g}(89 \%) . \mathrm{C}_{8} \mathrm{H}_{18} \mathrm{ClNO}_{2}, \mathrm{M}_{\mathrm{r}}=195.7$. Exact MS (APCI): $\mathrm{m} / \mathrm{z}=160.1380$ (calcd. 160.1332 for $\mathrm{C}_{8} \mathrm{H}_{18} \mathrm{NO}_{2}\left[\mathrm{MH}^{+}\right]$). ${ }^{1} \mathrm{H}$ NMR (DMSO-d $): \delta[\mathrm{ppm}]=0.94(\mathrm{~d}, J=6.7 \mathrm{~Hz}, 6 \mathrm{H}$, $\left.\mathrm{NCH}_{2} \mathrm{CH}\left(\mathrm{CH}_{3}\right)_{2}\right), 1.90$ - $2.05\left(\mathrm{~m}, 1 \mathrm{H}, \mathrm{NCH}_{2} \mathrm{CH}\left(\mathrm{CH}_{3}\right)_{2}\right), 2.75$ (d, $\left.J=7.1 \mathrm{~Hz}, 2 \mathrm{H}, \mathrm{NCH}_{2} \mathrm{CH}\left(\mathrm{CH}_{3}\right)_{2}\right), 2.83$ (t, $J=7.5 \mathrm{~Hz}, 2 \mathrm{H}, \mathrm{CH}_{2} \mathrm{CH}_{2} \mathrm{CO}_{2} \mathrm{CH}_{3}$ ), 3.12 (t, $\left.J=7.4 \mathrm{~Hz}, 2 \mathrm{H}, \mathrm{CH}_{2} \mathrm{CH}_{2} \mathrm{CO}_{2} \mathrm{CH}_{3}\right), 3.64$ (s, 3H, $\mathrm{CO}_{2} \mathrm{CH}_{3}$ ), $8.88\left(\mathrm{~s}, 2 \mathrm{H}, \mathrm{NH}_{2}\right) .{ }^{13} \mathrm{C} \mathrm{NMR}\left(\mathrm{DMSO}-d_{6}\right): \delta[\mathrm{ppm}]=19.9\left(2 \mathrm{C}, \mathrm{NCH}_{2} \mathrm{CH}\left(\mathrm{CH}_{3}\right)_{2}\right), 25.2(1 \mathrm{C}$, $\left.\mathrm{NCH}_{2} \mathrm{CH}\left(\mathrm{CH}_{3}\right)_{2}\right), 29.8$ (1C, $\left.\mathrm{CH}_{2} \mathrm{CH}_{2} \mathrm{CO}_{2} \mathrm{CH}_{3}\right), 42.6$ (1C, $\left.\mathrm{CH}_{2} \mathrm{CH}_{2} \mathrm{CO}_{2} \mathrm{CH}_{3}\right), 51.7$ (1C, $\left.\mathrm{CO}_{2} \mathrm{CH}_{3}\right), 53.7$ (1C, $\left.\mathrm{NCH}_{2} \mathrm{CH}\left(\mathrm{CH}_{3}\right)_{2}\right), 170.4$ (1C, $\left.\mathrm{CO}_{2} \mathrm{CH}_{3}\right)$. IR (neat): $v$ [cm $\left.{ }^{-1}\right]=1736(\mathrm{C}=\mathrm{O}), 1593(\mathrm{C}-\mathrm{N})$.

\subsubsection{Methyl 2-\{N-isobutyl- $N$-[2-(methoxycarbonyl)ethyl]-carbamoyl\}-benzoate (8)}

Monomethyl phthalate (7, $6.24 \mathrm{~g}, 34.6 \mathrm{mmol})$ was added to a vigorously stirred solution of $\mathrm{SOCl}_{2}(6.18$ 
g, $52 \mathrm{mmol}, 3.77 \mathrm{~mL})$ in $\mathrm{CH}_{2} \mathrm{Cl}_{2}(20 \mathrm{~mL})$ and the mixture was heated to reflux for $1.5 \mathrm{~h}$. The reflux condenser was replaced by a Liebig micro distillation apparatus to remove $\mathrm{CH}_{2} \mathrm{Cl}_{2}$ and $\mathrm{SOCl}_{2}$. The residue was dissolved in $\mathrm{CH}_{2} \mathrm{Cl}_{2}$ (20 mL). Then pyridine (8.21 g, $104 \mathrm{mmol}, 8.4 \mathrm{~mL}, 3$ equiv.) and 6• $\mathrm{HCl}$ (8.13 g, $41.5 \mathrm{mmol}, 1.2$ equiv.) were added under ice cooling. After $4 \mathrm{~h}$, the mixture was concentrated in vacuo, the residue was suspended in sat. $\mathrm{NaHCO}_{3}$ and the mixture was extracted with $\mathrm{CH}_{2} \mathrm{Cl}_{2}(3 \times 50 \mathrm{~mL})$. The combined organic layers were dried $\left(\mathrm{Na}_{2} \mathrm{SO}_{4}\right)$, concentrated in vacuo and the residue was purified by fc $\left(\varnothing=8 \mathrm{~cm}, \mathrm{~h}=16 \mathrm{~cm}\right.$, cyclohexane $/$ ethyl acetate $\left.=2: 1, R_{\mathrm{f}}=0.45\right)$ to give 8 as a colorless solid, mp $62{ }^{\circ} \mathrm{C}$, yield $7.12 \mathrm{~g}(64 \%) . \mathrm{C}_{17} \mathrm{H}_{23} \mathrm{NO}_{5}, \mathrm{M}_{\mathrm{r}}=321.4$. Exact MS (APCI): $\mathrm{m} / \mathrm{z}=$ 322.1659 (calcd. 322.1649 for $\left.\mathrm{C}_{17} \mathrm{H}_{24} \mathrm{NO}_{5}\left[\mathrm{MH}^{+}\right]\right) .{ }^{1} \mathrm{H}$ NMR $\left(\mathrm{CDCl}_{3}\right)$ : $\delta[\mathrm{ppm}]=0.76$ (d, $J=6.7 \mathrm{~Hz}, 6 \mathrm{H}$, $\left.\mathrm{NCH}_{2} \mathrm{CH}\left(\mathrm{CH}_{3}\right)_{2}\right), 1.81-1.92\left(\mathrm{~m}, 1 \mathrm{H}, \mathrm{NCH}_{2} \mathrm{CH}\left(\mathrm{CH}_{3}\right)_{2}\right), 2.79-2.91$ (m, 4H, $\left.\mathrm{CH}_{2} \mathrm{CH}_{2} \mathrm{CO}_{2} \mathrm{CH}_{3}\right), 3.72(\mathrm{~s}$, $3 \mathrm{H}, \mathrm{CH}_{2} \mathrm{CH}_{2} \mathrm{CO}_{2} \mathrm{CH}_{3}$ ), 3.73 - 3.86 (m, 2H, $\left.\mathrm{NCH}_{2} \mathrm{CH}\left(\mathrm{CH}_{3}\right)_{2}\right)$, 3.86 (s, 3H, $\mathrm{ArCO}_{2} \mathrm{CH}_{3}$ ), 7.28 (dd, $J=$ 7.9/1.0 Hz, 1H, Ar-H), 7.40 - 7.45 (m, 1H, Ar-H), 7.53 - 7.56 (m, 1H, Ar-H), 7.97 - 8.05 (m, 1H, Ar$H) .{ }^{13} \mathrm{C} \mathrm{NMR}\left(\mathrm{CDCl}_{3}\right): \delta[\mathrm{ppm}]=20.1\left(2 \mathrm{C}, \mathrm{NCH}_{2} \mathrm{CH}\left(\mathrm{CH}_{3}\right)_{2}\right), 27.1\left(1 \mathrm{C}, \mathrm{NCH}_{2} \mathrm{CH}\left(\mathrm{CH}_{3}\right)_{2}\right), 31.4(1 \mathrm{C}$, $\mathrm{CH}_{2} \mathrm{CH}_{2} \mathrm{CO}_{2} \mathrm{CH}_{3}$ ), 41.2 (1C, $\mathrm{NCH}_{2} \mathrm{CH}\left(\mathrm{CH}_{3}\right)_{2}$ ), 51.7 (1C, $\mathrm{CH}_{2} \mathrm{CH}_{2} \mathrm{CO}_{2} \mathrm{CH}_{3}$ ), 52.3 (1C, $\mathrm{ArCO}_{2} \mathrm{CH}_{3}$ ), 56.2 (1C, $\mathrm{CH}_{2} \mathrm{CH}_{2} \mathrm{CO}_{2} \mathrm{CH}_{3}$ ), 127.7 (1C, Ar-C), 128.5 (1C, Ar-C), 128.7 (1C, Ar-C), 130.4 (1C, Ar-C), 132.6 (1C, Ar-C), 132.7 (1C, Ar-C), 165.8 (1C, $\mathrm{ArCO}_{2} \mathrm{CH}_{3}$ ), 171.4 (1C, CONR $), 172.8$ (1C, $\left.\mathrm{CO}_{2} \mathrm{CH}_{3}\right)$. IR (neat): $v\left[\mathrm{~cm}^{-1}\right]=1725(\mathrm{C}=\mathrm{O}), 1625(\mathrm{NC}=\mathrm{O})$.

\subsubsection{Methyl 2-isobutyl-5-hydroxy-1-oxo-2,3-dihydro-1H-2-benzazepine-4-carboxylate (9)}

Under ice cooling a dispersion of $\mathrm{NaH}(60 \% \mathrm{w} / \mathrm{w}$ in mineral oil $540 \mathrm{mg}, 13.5 \mathrm{mmol})$ was added slowly to a solution of the amide $8(1.41 \mathrm{~g}, 4.5 \mathrm{mmol})$ in THF $(20 \mathrm{~mL})$ and left to stir for $0.5 \mathrm{~h}$, then mixture was heated to reflux for $1.5 \mathrm{~h}$. After cooling to rt the mixture was concentrated in vacuo and the residue was suspended in $1 \mathrm{M} \mathrm{HCl}$. The aqueous layer was extracted with $\mathrm{CH}_{2} \mathrm{Cl}_{2}(3 \times 50 \mathrm{~mL})$. The combined organic layers were dried $\left(\mathrm{Na}_{2} \mathrm{SO}_{4}\right)$, concentrated in vacuo and the residue was purified by automatic fc 
(Biotage $^{\circledR}$, Cartridge SNAP 100 g, cyclohexane / ethyl acetate, $R_{\mathrm{f}}=0.35$ (cyclohexane $/$ ethyl acetate $=2$

: 1)) to give the 2-benzazepine 9 as a pale yellow solid, mp $84{ }^{\circ} \mathrm{C}$, yield $750 \mathrm{mg}(58 \%) . \mathrm{C}_{16} \mathrm{H}_{19} \mathrm{NO}_{4}$, $\mathrm{M}_{\mathrm{r}}=$ 289.3. Exact MS (APCI): $m / z=290.1387$ (calcd. 290.1392 for $\mathrm{C}_{16} \mathrm{H}_{20} \mathrm{NO}_{4}\left[\mathrm{MH}^{+}\right]$). ${ }^{1} \mathrm{H} \mathrm{NMR}$

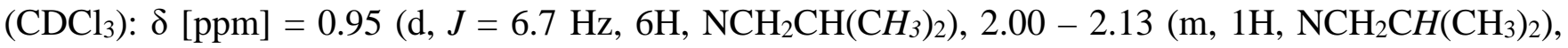
3.23 - 3.38 (m, 1H, $\left.\mathrm{NCH}_{2} \mathrm{CH}\left(\mathrm{CH}_{3}\right)_{2}\right)$, 3.45 - 3.61 (m, 1H, $\left.\mathrm{NCH}_{2} \mathrm{CH}\left(\mathrm{CH}_{3}\right)_{2}\right), 3.68$ - 3.82 (m, 1H, 3- $\left.\mathrm{CH}_{2}\right)$, 3.90 (s, 3H, $\left.\mathrm{CO}_{2} \mathrm{CH}_{3}\right), 4.01$ - 4.17 (m, 1H, 3- $\left.\mathrm{CH}_{2}\right), 7.53$ - 7.61 (m, 2H, Ar-H), 7.84 - 7.90 (m, 1H, Ar-H), 7.98 - 8.03 (m, 1H, Ar-H), 12.56 (s, $1 \mathrm{H}, \mathrm{OH}) .{ }^{13} \mathrm{C} \mathrm{NMR}\left(\mathrm{CDCl}_{3}\right): \delta[\mathrm{ppm}]=20.3\left(2 \mathrm{C}, \mathrm{NCH}_{2} \mathrm{CH}\left(\mathrm{CH}_{3}\right)_{2}\right)$, 27.7 (1C, $\left.\mathrm{NCH}_{2} \mathrm{CH}\left(\mathrm{CH}_{3}\right)_{2}\right)$, 43.6 (1C, C-3), 52.4 (1C, $\left.\mathrm{CO}_{2} \mathrm{CH}_{3}\right), 55.8$ (1C, $\left.\mathrm{NCH}_{2} \mathrm{CH}\left(\mathrm{CH}_{3}\right)_{2}\right), 102.3$ (1C, C-4), 127 (1C, Ar-C), 130.6 (1C, Ar-C), 130.9 (1C, Ar-C), 131.2 (1C, Ar-C), 131.3 (1C, Ar-C), 136.3 (1C, Ar-C), 167.8 (1C, CONR 2 ), 170.4 (1C, $\left.\mathrm{CO}_{2} \mathrm{CH}_{3}\right), 171.2$ (1C, C-5). IR (neat): v [ $\left.\mathrm{cm}^{-1}\right]=1728$ $(\mathrm{C}=\mathrm{O}), 1632(\mathrm{C}=\mathrm{O}), 1611(\mathrm{NC}=\mathrm{O})$.

\subsubsection{Methyl 2-isobutyl-5-hydroxy-1-oxo-2,3,4,5-tetrahydro-1H-2-benzazepine-4-carboxylate (10)}

$\mathrm{NaBH}_{4}$ (523 mg, $13.8 \mathrm{mmol}$ ) was added slowly to a solution of the enol ester 9 (2.0 g, $\left.6.91 \mathrm{mmol}\right)$ in abs. $\mathrm{H}_{3} \mathrm{COH}(50 \mathrm{~mL})$ under ice cooling. After $1 \mathrm{~h}, 1 \mathrm{M} \mathrm{HCl}(50 \mathrm{~mL})$ was added and the mixture was extracted with $\mathrm{CH}_{2} \mathrm{Cl}_{2}(3 \times 50 \mathrm{~mL})$. The combined organic layers were dried $\left(\mathrm{Na}_{2} \mathrm{SO}_{4}\right)$, concentrated in vacuo and the residue was purified by fc $\left(\varnothing=3 \mathrm{~cm}, \mathrm{~h}=16 \mathrm{~cm}\right.$, cyclohexane $/$ ethyl acetate $=4: 1, \mathrm{R}_{\mathrm{f}}=$ 0.18 ) to give 10 as a colorless solid, mp $154{ }^{\circ} \mathrm{C}$, yield $1.16 \mathrm{~g}(58 \%) . \mathrm{C}_{16} \mathrm{H}_{21} \mathrm{NO}_{4}, \mathrm{M}_{\mathrm{r}}=291.4$. Exact MS (APCI): $m / z=292.1590$ (calcd. 292.1543 for $\left.\mathrm{C}_{16} \mathrm{H}_{22} \mathrm{NO}_{4}\left[\mathrm{MH}^{+}\right]\right) .{ }^{1} \mathrm{H}$ NMR $\left(\mathrm{CDCl}_{3}\right): \delta[\mathrm{ppm}]=0.92(\mathrm{~d}$, $\left.J=6.7 \mathrm{~Hz}, 6 \mathrm{H}, \mathrm{NCH}_{2} \mathrm{CH}\left(\mathrm{CH}_{3}\right)_{2}\right), 1.98-2.06\left(\mathrm{~m}, 1 \mathrm{H}, \mathrm{NCH}_{2} \mathrm{CH}\left(\mathrm{CH}_{3}\right)_{2}\right), 3.19-3.36(\mathrm{~m}, 5 \mathrm{H}$, $\left.\mathrm{NCH}_{2} \mathrm{CH}\left(\mathrm{CH}_{3}\right)_{2}, 3-\mathrm{CH}_{2}, 4-\mathrm{CH}\right), 3.68$ (s, 3H, $\left.\mathrm{CO}_{2} \mathrm{CH}_{3}\right), 4.60$ (d, J = 6.7 Hz, 1H, 5-CH), 7.30 - 7.40 (m, 1H, Ar- $H$ ), $7.41-7.48(\mathrm{~m}, 2 \mathrm{H}, \mathrm{Ar}-H), 7.63(\mathrm{~d}, J=7.3 \mathrm{~Hz}, 1 \mathrm{H}, \mathrm{Ar}-H)$. A signal for OH proton is not seen in the spectrum. ${ }^{13} \mathrm{C}$ NMR $\left(\mathrm{CDCl}_{3}\right): \delta[\mathrm{ppm}]=20.5\left(2 \mathrm{C}, \mathrm{NCH}_{2} \mathrm{CH}\left(\mathrm{CH}_{3}\right)_{2}\right), 27.8(1 \mathrm{C}$, $\left.\mathrm{NCH}_{2} \mathrm{CH}\left(\mathrm{CH}_{3}\right)_{2}\right), 48.1$ (1C, $\left.\mathrm{NCH}_{2} \mathrm{CHCO}_{2} \mathrm{CH}_{3}\right), 51.6$ (1C, C-3), 52.1 (1C, $\left.\mathrm{CO}_{2} \mathrm{CH}_{3}\right), 55.1$ (1C, C-4), 
70.2 (1C, C-5), 125.1 (1C, Ar-C), 128.2 (1C, Ar-C), 128.5 (1C, Ar-C), 130.9 (1C, Ar-C), 133.2 (1C, ArC), 138.1 (1C, Ar-C), 171.1 (1C, $C-1), 171.5$ (1C, $\left.C_{2} \mathrm{CH}_{3}\right)$. IR (neat): v [cm-1] = $3221(-\mathrm{OH}), 1725$ $(\mathrm{C}=\mathrm{O}), 1620(\mathrm{NC}=\mathrm{O})$.

\subsubsection{Methyl 2-isobutyl-1-oxo-2,3-dihydro-1H-2-benzazepine-4-carboxylate (11)}

Under ice cooling $\mathrm{CH}_{3} \mathrm{SO}_{2} \mathrm{Cl}$ (1117 mg, $9.75 \mathrm{mmol}$ ) was added to a solution of $\beta$-hydroxy ester 10 (943.5 mg, $3.25 \mathrm{mmol}$ ) and triethylamine (986 mg, $9.75 \mathrm{mmol}$ ) in $\mathrm{CH}_{2} \mathrm{Cl}_{2}(20 \mathrm{~mL}$ ). The reaction mixture was stirred overnight at rt. Then DBU (2.47 g, $16.3 \mathrm{mmol})$ was added under ice cooling. The reaction mixture was stirred for $1 \mathrm{~h}$ at rt. Then $1 \mathrm{M} \mathrm{HCl}$ was added and the mixture was extracted with $\mathrm{CH}_{2} \mathrm{Cl}_{2}$ (3 x $50 \mathrm{~mL})$. The combined organic layers were dried $\left(\mathrm{Na}_{2} \mathrm{SO}_{4}\right)$, concentrated in vacuo and the residue was purified by $\mathrm{fc}\left(\varnothing=3 \mathrm{~cm}, \mathrm{~h}=16 \mathrm{~cm}\right.$, cyclohexane $/$ ethyl acetate $\left.=4: 1, \mathrm{R}_{\mathrm{f}}=0.6\right)$ to give $\mathbf{1 1}$ as a colorless solid, mp $69^{\circ} \mathrm{C}$, yield $679 \mathrm{mg}(76 \%) . \mathrm{C}_{16} \mathrm{H}_{20} \mathrm{NO}_{3}, \mathrm{M}_{\mathrm{r}}=273.3$. Exact $\mathrm{MS}(\mathrm{APCI}): \mathrm{m} / \mathrm{z}=$ 274.1500 (calcd. 274.1432 for $\left.\mathrm{C}_{16} \mathrm{H}_{21} \mathrm{NO}_{3}\left[\mathrm{MH}^{+}\right]\right) .{ }^{1} \mathrm{H}$ NMR $\left(\mathrm{CDCl}_{3}\right): \delta[\mathrm{ppm}]=0.93(\mathrm{~d}, J=6.7 \mathrm{~Hz}, 6 \mathrm{H}$, $\left.\mathrm{NCH}_{2} \mathrm{CH}\left(\mathrm{CH}_{3}\right)_{2}\right), 2.01-2.13\left(\mathrm{~m}, 1 \mathrm{H}, \mathrm{NCH}_{2} \mathrm{CH}\left(\mathrm{CH}_{3}\right)_{2}\right), 3.44$ (d, $\left.J=7.6 \mathrm{~Hz}, 2 \mathrm{H}, \mathrm{NCH}_{2} \mathrm{CH}\left(\mathrm{CH}_{3}\right)_{2}\right), 3.88$ (s, 3H, $\mathrm{CO}_{2} \mathrm{CH}_{3}$ ), 3.97 (s, 2H, 3-CH2), 7.34 (dd, $J=5.9 / 3.7 \mathrm{~Hz}, 1 \mathrm{H}, \mathrm{Ar}-\mathrm{H}$ ), 7.50 (dd, $J=6.0 / 3.7 \mathrm{~Hz}, 2 \mathrm{H}$, Ar-H), 7.82 (s, 1H, 5-CH), 8.09 (dd, $J=5.8 / 3.5 \mathrm{~Hz}, 1 \mathrm{H}, \mathrm{Ar}-H) .{ }^{13} \mathrm{C}$ NMR $\left(\mathrm{CDCl}_{3}\right): \delta[\mathrm{ppm}]=20.2(2 \mathrm{C}$, $\left.\mathrm{NCH}_{2} \mathrm{CH}\left(\mathrm{CH}_{3}\right)_{2}\right), 27.7$ (1C, $\left.\mathrm{NCH}_{2} \mathrm{CH}\left(\mathrm{CH}_{3}\right)_{2}\right), 44.4$ (1C, C-3), 52.6 (1C, $\left.\mathrm{NCH}_{2} \mathrm{CH}\left(\mathrm{CH}_{3}\right)_{2}\right), 56.3$ (1C, $\mathrm{CO}_{2} \mathrm{CH}_{3}$ ), 129.7 (1C, Ar-C), 129.9 (1C, Ar- $C$ ), 130.5 (1C, Ar- $C$ ), 131.8 (1C, Ar-C), 132.9 (1C, Ar-C), 133.2 (1C, Ar-C), 136.8 (1C, $C-4), 141.7$ (1C, $C-5), 166.1$ (1C, $\left.C_{2} \mathrm{CH}_{3}\right), 168.1$ (1C, $C$-1). IR (neat): v $\left[\mathrm{cm}^{-1}\right]=2924\left(\mathrm{C}-\mathrm{H}_{\text {aliph. }}\right), 1725(\mathrm{C}=\mathrm{O}), 1597(\mathrm{C}=\mathrm{C})$.

\subsubsection{2-Isobutyl-1-oxo-2,3-dihydro-1H-2-benzazepine-4-carboxylic acid (12)}

The ester 11 (120 mg, $0.44 \mathrm{mmol})$ was dissolved in $\mathrm{H}_{3} \mathrm{COH}(10 \mathrm{~mL})$ and $5 \mathrm{M} \mathrm{NaOH}(10 \mathrm{~mL})$ was added. The mixture was heated to reflux for $40 \mathrm{~min}$. After cooling down to $0{ }^{\circ} \mathrm{C}$, the mixture was 
acidified with conc. $\mathrm{HCl}(2.5 \mathrm{~mL})$ and extracted with ethyl acetate $(3 \times 50 \mathrm{~mL})$. The combined organic layers were dried $\left(\mathrm{Na}_{2} \mathrm{SO}_{4}\right)$ and concentrated in vacuo to give the acid $\mathbf{1 2}$. Colorless solid, mp $192{ }^{\circ} \mathrm{C}$, yield $114 \mathrm{mg}(100 \%) . \mathrm{C}_{15} \mathrm{H}_{17} \mathrm{NO}_{3}, \mathrm{M}_{\mathrm{r}}=259.3 . \mathrm{R}_{\mathrm{f}}=0.12$ (cyclohexane / ethyl acetate = $2: 1$ ). Exact MS (APCI): $m / z=260.1285$ (calcd. 260.1281, for $\mathrm{C}_{15} \mathrm{H}_{18} \mathrm{NO}_{3}\left[\mathrm{MH}^{+}\right]$). ${ }^{1} \mathrm{H}$ NMR (methanol- $\left.d_{4}\right): \delta$ [ppm] $=$ $0.94\left(\mathrm{~d}, J=6.7 \mathrm{~Hz}, 6 \mathrm{H}, \mathrm{NCH}_{2} \mathrm{CH}\left(\mathrm{CH}_{3}\right)_{2}\right), 2.05$ - 2.18 (m, 1H, $\left.\mathrm{NCH}_{2} \mathrm{CH}\left(\mathrm{CH}_{3}\right)_{2}\right), 3.46$ (d, $J=7.6 \mathrm{~Hz}, 2 \mathrm{H}$, $\left.\mathrm{NCH}_{2} \mathrm{CH}\left(\mathrm{CH}_{3}\right)_{2}\right), 4.01$ (s, 2H, 3- $\mathrm{CH}_{2}$ ), 7.50 (dd, $J=7 . / 1.5 \mathrm{~Hz}, 1 \mathrm{H}, \mathrm{Ar}-H$ ), 7.53 - 7.63 (m, 2H, Ar-H), 7.91 (s, $1 \mathrm{H}, 5-H$ ), 7.99 (dd, $J=7.7 / 1.6 \mathrm{~Hz}, 1 \mathrm{H}, \mathrm{Ar}-H$ ). A signal for $\mathrm{COOH}$ proton is not seen in the spectrum. ${ }^{13} \mathrm{C}$ NMR (methanol- $\left.d_{4}\right): \delta[\mathrm{ppm}]=20.4\left(2 \mathrm{C}, \mathrm{N}-\mathrm{CH}_{2}-\mathrm{CH}-\left(\mathrm{CH}_{3}\right)_{2}\right), 28.8\left(1 \mathrm{C}, \mathrm{N}-\mathrm{CH}_{2}-\mathrm{CH}-\right.$ $\left.\left(\mathrm{CH}_{3}\right)_{2}\right), 45.4$ (1C, $\left.\mathrm{C}-3\right), 57.2$ (1C, N-CH $\left.2-\mathrm{CH}-\left(\mathrm{CH}_{3}\right)_{2}\right), 130.7$ (1C, Ar-C), 131.1 (1C, Ar-C), 132.0 (1C, Ar-C), 132.1 (1C, Ar-C), 135.0 (1C, C-4), 135.30 (1C, Ar-C), 137.11 (1C, Ar-C), 142.00 (1C, C-5), 168.2 (1C, $\left.\mathrm{CO}_{2} \mathrm{CH}_{3}\right), 170.2$ (1C, $\left.\mathrm{C}-1\right)$. IR (neat): $v\left[\mathrm{~cm}^{-1}\right]=2937\left(\mathrm{C}-\mathrm{H}_{\text {aliph. }}\right), 1715(\mathrm{C}=\mathrm{O}), 1600(\mathrm{C}=\mathrm{C})$. HPLC (method 1): $\mathrm{t}_{\mathrm{R}}=17.21$ min, purity $98.8 \%$.

\subsubsection{2-Isobutyl- $N$-(\{[N-methyl- $N$-(tetrahydro-2H-pyran-4-yl)amino]methyl $\}$ phenyl)-1-oxo-2,3-}

\section{dihydro-1H-2-benzazepine-4-carboxamide (14)}

Amine 13 (113 mg, $0.44 \mathrm{mmol}$ ) was added to a vigorously stirred mixture of acid 12 (113.8 mg, 0.44 mmol), NEt3 (89.1 mg, $0.88 \mathrm{mmol})$ and HATU (182.5 mg, $0.48 \mathrm{mmol})$ in abs. THF (5 mL). The mixture was stirred overnight at rt. Then the mixture was concentrated in vacuo. Saturated $\mathrm{NaHCO}_{3}$-solution (20 $\mathrm{mL}$ ) was added to the residue and the mixture was extracted with $\mathrm{CH}_{2} \mathrm{Cl}_{2}$ (3 $\mathrm{x} 20 \mathrm{~mL}$ ). The combined organic layers were concentrated in vacuo to give a yellow solid, which was purified by fc $(\varnothing=1.5 \mathrm{~cm}$, $\left.\mathrm{h}=20 \mathrm{~cm}, \mathrm{CH}_{2} \mathrm{Cl}_{2}: \mathrm{H}_{3} \mathrm{COH}=9: 1+1 \% \mathrm{NH}_{3}, \mathrm{~V}=30 \mathrm{~mL}, \mathrm{R}_{\mathrm{f}}=0.66\right)$ and then by automatic fc (Biotage $^{\circledR}$, SNAP Cartridge KP-C18-HS 30 g, water/acetonitrile) to give 14. Colorless solid, yield $97 \mathrm{mg}$ (48\%). $\mathrm{C}_{28} \mathrm{H}_{35} \mathrm{~N}_{3} \mathrm{O}_{3}, \mathrm{M}_{\mathrm{r}}=461.6$. Exact MS (APCI): $m / z=462.2709$ (calcd. 462.2678 for $\mathrm{C}_{28} \mathrm{H}_{36} \mathrm{~N}_{3} \mathrm{O}_{3}$ $\left.\left[\mathrm{MH}^{+}\right]\right) .{ }^{1} \mathrm{H} \mathrm{NMR}\left(\mathrm{CDCl}_{3}\right): \delta[\mathrm{ppm}]=0.84\left(\mathrm{~d}, J=6.6 \mathrm{~Hz}, 6 \mathrm{H}, \mathrm{NCH}_{2} \mathrm{CH}\left(\mathrm{CH}_{3}\right)_{2}\right), 1.64-1.77(\mathrm{~m}, 2 \mathrm{H}, 3-$ 
$\mathrm{CH}_{\text {pyran, }}$ 5- $\left.\mathrm{CH}_{\text {pyran}}\right), 1.77-1.86\left(\mathrm{~m}, 2 \mathrm{H}, 3-\mathrm{CH}_{\text {pyran, }}\right.$ 5- $\left.\left.\mathrm{CH}_{\text {pyran }}\right), 1.91-2.04\left(\mathrm{~m}, 1 \mathrm{H}, \mathrm{NCH}_{2} \mathrm{CH}_{(} \mathrm{CH}_{3}\right)_{2}\right)$, 2.26 (s, 3H, $\left.\mathrm{CH}_{3}\right), 2.70-2.83\left(\mathrm{~m}, 1 \mathrm{H}, 4-\mathrm{CH}_{\text {pyran }}\right), 3.34$ (d, $\left.J=6.8 \mathrm{~Hz}, 2 \mathrm{H}, \mathrm{NCH}_{2} \mathrm{CH}\left(\mathrm{CH}_{3}\right)_{2}\right), 3.39(\mathrm{~d}, J=$ $11.4 \mathrm{~Hz}, 2 \mathrm{H}, 2-\mathrm{CH}_{\text {pyran, }}$ 6-CH $\mathrm{CH}_{\text {pyran}}$ ), 3.64 (s, 2H, $\mathrm{CH}_{2} \mathrm{~N}$ ), 3.91 (s, 2H, $\mathrm{CH}_{2} \mathrm{NCO}$ ), 4.04 (dd, $J=11.2 / 3.3$

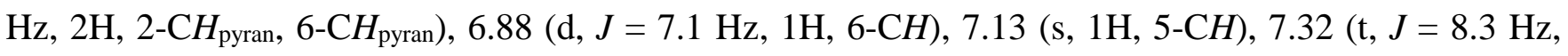

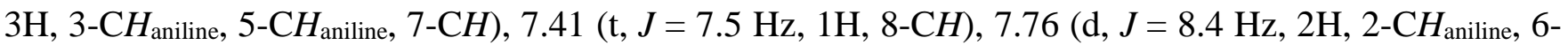
$\mathrm{CH}_{\text {aniline), }} 7.98$ (d, $\left.J=7.8 \mathrm{~Hz}, 1 \mathrm{H}, 9-\mathrm{CH}\right), 9.22$ (s, $\left.1 \mathrm{H}, \mathrm{NH}\right) .{ }^{13} \mathrm{C} \mathrm{NMR}\left(\mathrm{CDCl}_{3}\right): \delta[\mathrm{ppm}]=20.1(2 \mathrm{C}$, $\left.\mathrm{NCH}_{2} \mathrm{CH}\left(\mathrm{CH}_{3}\right)_{2}\right), 27.7$ (1C, $\left.\mathrm{NCH}_{2} \mathrm{CH}\left(\mathrm{CH}_{3}\right)_{2}\right), 29.1$ (2C, 3- $\mathrm{C}_{\text {pyran, 5- }}$ pyran), $37.4\left(1 \mathrm{C}, \mathrm{CH}_{3}\right), 44.6$ (1C, 3C), 56.2 (1C, $\left.\mathrm{NCH}_{2} \mathrm{CH}\left(\mathrm{CH}_{3}\right)_{2}\right)$, 57.4 (1C, $\left.\mathrm{CH}_{2} \mathrm{~N}\right), 59.9$ (1C, 4- $C_{\text {pyran }}$ ), 67.6 (2C, 2- $C_{\text {pyran, }}$ 6- $\left.C_{\text {pyran }}\right), 120.3$

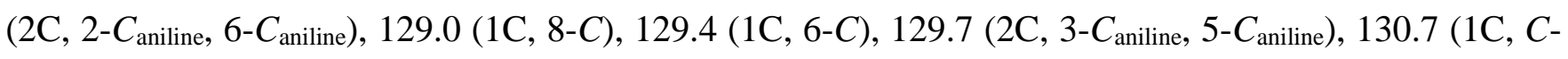
8), 130.7 (1C, C-9a), 130.9 (1C, C-9), 135.1 (1C, C-7), 134.4 (1C, C-4aniline), 135.7 (1C, C-5a), 137.8

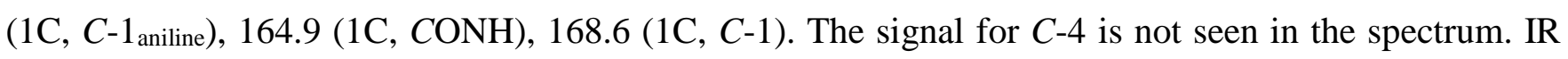
(neat): $v\left[\mathrm{~cm}^{-1}\right]=3300(\mathrm{NH}), 2939\left(\mathrm{CH}_{\text {aliph. }}\right), 1650(\mathrm{C}=\mathrm{O}), 1022(\mathrm{C}-\mathrm{O})$. HPLC (method 1): $\mathrm{t}_{\mathrm{R}}=20.62$ min, purity $98.4 \%$.

\section{4,3,8, 2-Isobutyl-1-oxo- $N$-\{4-[N-(thiazol-2-yl)sulfoamoyl]phenyl\}-2,3-dihydro-1H-2-benzazepine-4- carboxamide (16)}

Sulfathiazole (15, $47 \mathrm{mg}, 0.19 \mathrm{mmol}, 1$ equiv.) was added to a vigorously stirred mixture of 12 (48 mg, 0.19 mmol, 1 equiv.), $\mathrm{NEt}_{3}(51 \mu \mathrm{L}, 38 \mathrm{mg}, 0.37 \mathrm{mmol}, 2$ equiv.) and HATU (77 mg, $0.20 \mathrm{mmol}$, 1.1 equiv.) in abs. THF ( $3 \mathrm{~mL})$. The mixture was stirred overnight at rt. The solvent was removed in vacuo and a saturated solution of $\mathrm{NaHCO}_{3}(10 \mathrm{~mL})$ was added to the residue. The mixture was extracted with $\mathrm{CH}_{2} \mathrm{Cl}_{2}(2 \times 10 \mathrm{~mL})$ and ethyl acetate $(2 \times 10 \mathrm{~mL})$. The combined organic layers were dried $\left(\mathrm{Na}_{2} \mathrm{SO}_{4}\right)$ and concentrated in vacuo to give the crude product as yellow oil, which was purified by fc $\left(\varnothing=2 \mathrm{~cm}, \mathrm{~h}=16 \mathrm{~cm}, \mathrm{CH}_{2} \mathrm{Cl}_{2}: \mathrm{H}_{3} \mathrm{COH}=97: 3+1 \% \mathrm{NH}_{3}, \mathrm{~V}=10 \mathrm{~mL}, \mathrm{R}_{\mathrm{f}}=0.34\left(\mathrm{CH}_{2} \mathrm{Cl}_{2}:\right.\right.$ $\left.\mathrm{H}_{3} \mathrm{COH}=95: 5+1 \% \mathrm{NH}_{3}\right)$ ). Colorless oil, yield $7 \mathrm{mg}(8 \%) . \mathrm{C}_{24} \mathrm{H}_{24} \mathrm{~N}_{4} \mathrm{O}_{4} \mathrm{~S}_{2}, \mathrm{M}_{\mathrm{r}}=496.6$. Exact mass 
(APCI): $m / z=497.1296$ (calcd. 497.1312 for $\mathrm{C}_{24} \mathrm{H}_{25} \mathrm{~N}_{4} \mathrm{O}_{4} \mathrm{~S}_{2}\left[\mathrm{MH}^{+}\right]$). ${ }^{1} \mathrm{H}$ NMR (DMSO- $\left.d_{6}\right): \delta[\mathrm{ppm}]=$ $0.85\left(\mathrm{~d}, J=6.7 \mathrm{~Hz}, 6 \mathrm{H}, \mathrm{NCH}_{2} \mathrm{CH}\left(\mathrm{CH}_{3}\right)_{2}\right), 1.90-1.96\left(\mathrm{~m}, 1 \mathrm{H}, \mathrm{NCH}_{2} \mathrm{CH}\left(\mathrm{CH}_{3}\right)_{2}\right), 3.36(\mathrm{~d}, J=7.5 \mathrm{~Hz}$, 2H, $\left.\mathrm{NCH}_{2} \mathrm{CH}\left(\mathrm{CH}_{3}\right)_{2}\right), 3.93$ (s, 2H, 3- $\left.\mathrm{CH}_{2}\right), 6.83$ (d, $\left.J=4.6 \mathrm{~Hz}, 1 \mathrm{H}, 5-\mathrm{CH}_{\text {thiazole }}\right), 7.26$ (d, $J=4.6 \mathrm{~Hz}, 1 \mathrm{H}$, 4- $\mathrm{CH}_{\text {thiazole), }} 7.55$ (m, 2H, 6-CH, 8-CH), 7.62 (td, $\left.J=7.7 / 1.4 \mathrm{~Hz}, 1 \mathrm{H}, 7-\mathrm{CH}\right), 7.77$ (s, 1H, 5-CH), 7.79 (d,

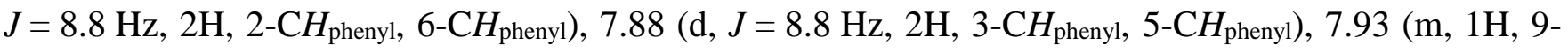
$\mathrm{CH}), 10.55(\mathrm{~s}, 1 \mathrm{H}, \mathrm{NH}), 12.70\left(\mathrm{~s}, 1 \mathrm{H}, \mathrm{SO}_{2} \mathrm{NH}\right) .{ }^{13} \mathrm{C}$ NMR $\left(\mathrm{DMSO}-d_{6}\right): \delta[\mathrm{ppm}]=19.9(2 \mathrm{C}$, $\left.\mathrm{NCH}_{2} \mathrm{CH}\left(\mathrm{CH}_{3}\right)_{2}\right), 27.2$ (1C, $\left.\mathrm{NCH}_{2} \mathrm{CH}\left(\mathrm{CH}_{3}\right)_{2}\right), 44.1$ (1C, $\left.\mathrm{C}-3\right), 55.0$ (1C, $\left.\mathrm{NCH}_{2} \mathrm{CH}\left(\mathrm{CH}_{3}\right)_{2}\right), 108.1$ (1C, $C$ -

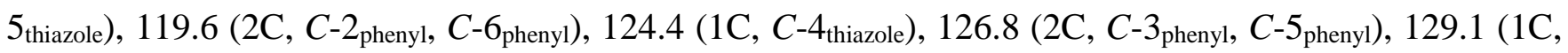
C-8), 129.6 (1C, C-6), 130.5 (1C, C-7), 131.0 (1C, C-9), 133.1 (1C, C-5a), 135.9 (1C, C-9a), 136.2 (1C, C-5), 136.8 (1C, C-4 $\left.4_{\text {phenyl }}\right), 137.0$ (1C, C-4), 142.2 (1C, C-1 $\left.1_{\text {phenyl }}\right), 165.0$ (1C, CONH), 167.0 (1C, C-1),

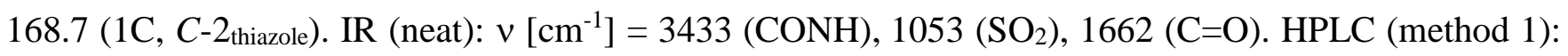
$t_{R}=18.68$ min, purity $96.8 \%$.

\subsubsection{Methyl 2-isobutyl-1-oxo-8-(p-tolyl)-2,3-dihydro-1H-2-benzazepine-4-carboxylate (24a)}

Under a permanent flow of $\mathrm{N}_{2}$, ester 23a (160 mg, $0.45 \mathrm{mmol}$ ), $\mathrm{PdCl}_{2}(\mathrm{dppf})$ (22 mg, $5 \mathrm{~mol} \%$ ), KOAc (104 mg, $1 \mathrm{mmol}$ ) and 4-methylbenzeneboronic acid (79 $\mathrm{mg}, 0.5 \mathrm{mmol}$ ) were suspended in dry dimethoxyethane $(10 \mathrm{~mL})$. The Schlenk tube was sealed and heated to $100{ }^{\circ} \mathrm{C}$ for $12 \mathrm{~h}$. After cooling down to rt, the mixture was filtered through a short silica pad (ethyl acetate). The filtrate was concentrated in vacuo to give the crude product as a brown oil, which was purified by automatic fc (Biotage $^{\circledR}$, SNAP 50 g, cyclohexane / ethyl acetate) to give 24a. Colorless solid, mp $124{ }^{\circ} \mathrm{C}$, yield $82 \mathrm{mg}$ (50\%). $\mathrm{C}_{23} \mathrm{H}_{25} \mathrm{NO}_{3}, \mathrm{M}_{\mathrm{r}}=363.5 .{ }^{1} \mathrm{H} \mathrm{NMR}\left(\mathrm{CDCl}_{3}\right): \delta[\mathrm{ppm}]=0.92\left(\mathrm{~d}, J=6.7 \mathrm{~Hz}, 6 \mathrm{H}, \mathrm{NCH}_{2} \mathrm{CH}\left(\mathrm{CH}_{3}\right)_{2}\right)$, $2.08-2.17$ (m, 1H, $\left.\mathrm{NCH}_{2} \mathrm{CH}\left(\mathrm{CH}_{3}\right)_{2}\right), 2.40$ (s, 3H, $\mathrm{CH}_{3}$ ), 3.51 (d, $\left.J=7.6 \mathrm{~Hz}, 2 \mathrm{H}, \mathrm{NCH}_{2} \mathrm{CH}\left(\mathrm{CH}_{3}\right)_{2}\right), 3.95$ (s, 3H, $\mathrm{CO}_{2} \mathrm{CH}_{3}$ ), 4.14 (s, 2H, 3- $\mathrm{CH}_{2}$ ), 7.28 - 7.36 (m, 2H, 3- $\mathrm{CH}_{\text {tolyl }}, 5-\mathrm{CH}_{\text {tolyl }}$ ), 7.47 - 7.65 (m, 3H, 2$\left.\mathrm{CH}_{\text {tolyl }}, 6-\mathrm{CH}_{\text {tolyl }}\right), 7.64$ (dd, $\left.J=8.2 / 2.0 \mathrm{~Hz}, 1 \mathrm{H}, 7-\mathrm{CH}\right), 7.71$ (dd, $\left.J=8.2 / 2.1 \mathrm{~Hz}, 1 \mathrm{H}, 6-\mathrm{CH}\right), 7.89(\mathrm{~s}, 1 \mathrm{H}$, 
5-CH), 8.20 (s, $1 \mathrm{H}, 9-\mathrm{CH}) .{ }^{13} \mathrm{C} \mathrm{NMR}\left(\mathrm{CDCl}_{3}\right): \delta[\mathrm{ppm}]=20.2\left(2 \mathrm{C}, \mathrm{NCH}_{2} \mathrm{CH}\left(\mathrm{CH}_{3}\right)_{2}\right), 21.3\left(1 \mathrm{C}, \mathrm{CH}_{3}\right)$, 27.8 (1C, $\left.\mathrm{NCH}_{2} \mathrm{CH}\left(\mathrm{CH}_{3}\right)_{2}\right), 44.5$ (1C, $\left.C-3\right), 52.6$ (1C, $\left.\mathrm{CO}_{2} \mathrm{CH}_{3}\right), 56.4$ (1C, $\left.\mathrm{NCH}_{2} \mathrm{CH}\left(\mathrm{CH}_{3}\right)_{2}\right), 124.3$ (1C,

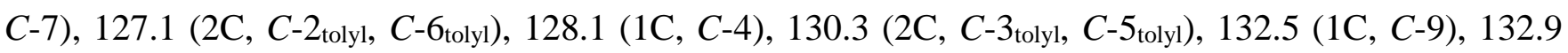
(1C, C-9a), 134.6 (1C, C-4 tolyl $\left._{1}\right), 138.0$ (1C, C-5a), 138.8 (1C, C-1 tolyl $\left._{1}\right), 141.9$ (1C, C-6), 149.2 (1C, C-8), 168.1 (1C, $\left.\mathrm{CO}_{2} \mathrm{CH}_{3}\right), 170.0$ (1C, C-1). IR (neat): $v\left[\mathrm{~cm}^{-1}\right]=2937\left(\mathrm{C}-\mathrm{H}_{\text {aliph. }}\right), 1728\left(\mathrm{C}=\mathrm{O}_{\text {amide }}\right), 1600$ $(\mathrm{C}=\mathrm{C})$.

\subsubsection{Methyl 2-isobutyl-1-oxo-7-(p-tolyl)-2,3-dihydro-1H-2-benzazepine-4-carboxylate (24b)}

Under a permanent flow of $\mathrm{N}_{2}$, ester 23b (160 mg, $0.45 \mathrm{mmol}$ ), $\mathrm{PdCl}_{2}(\mathrm{dppf})$ (22 mg, $5 \mathrm{~mol} \%$ ), KOAc (104 mg, $1 \mathrm{mmol}$ ) and 4-methylbenzeneboronic acid (79 mg, $0.5 \mathrm{mmol}$ ) were suspended in dry dimethoxyethane $(10 \mathrm{~mL})$. The Schlenk tube was sealed and heated to $100{ }^{\circ} \mathrm{C}$ for $12 \mathrm{~h}$. After cooling down to rt, the mixture was filtered through a short silica pad (ethyl acetate). The filtrate was concentrated in vacuo and purified by automatic fc (Biotage ${ }^{\circledR}$, SNAP 50 g, cyclohexane / ethyl acetate) to give 24b. Colorless solid, mp $128{ }^{\circ} \mathrm{C}$, yield $95 \mathrm{mg}(58 \%) . \mathrm{C}_{23} \mathrm{H}_{25} \mathrm{NO}_{3}, \mathrm{M}_{\mathrm{r}}=363.5 .{ }^{1} \mathrm{H} \mathrm{NMR}\left(\mathrm{CDCl}_{3}\right)$ : $\delta[\mathrm{ppm}]=0.94\left(\mathrm{~d}, J=6.7 \mathrm{~Hz}, 6 \mathrm{H}, \mathrm{NCH}_{2} \mathrm{CH}\left(\mathrm{CH}_{3}\right)_{2}\right), 2.02-2.15\left(\mathrm{~m}, 1 \mathrm{H}, \mathrm{NCH}_{2} \mathrm{CH}\left(\mathrm{CH}_{3}\right)_{2}\right), 2.41(\mathrm{~s}, 3 \mathrm{H}$, $\mathrm{CH}_{3}$ ), 3.46 (d, $\left.J=7.6 \mathrm{~Hz}, 2 \mathrm{H}, \mathrm{NCH}_{2} \mathrm{CH}\left(\mathrm{CH}_{3}\right)_{2}\right), 3.89$ (s, 3H, $\mathrm{CO}_{2} \mathrm{CH}_{3}$ ), 4.02 (s, 2H, 3- $\mathrm{CH}_{2}$ ), $7.26-7.30$ (m, 2H, 3-CH $\left.\mathrm{CH}_{\text {tolyl }}, 5-\mathrm{CH}_{\text {tolyl }}\right), 7.47-7.61$ (m, 3H, 2-CH $\mathrm{CH}_{\text {tolyl }}, 6-\mathrm{CH}_{\text {tolyl }}, 6-\mathrm{CH}$ ), 7.71 (dd, $J=8.2 / 1.8 \mathrm{~Hz}$, 1H, 8-CH), 7.88 (s, 1H, 5-CH), $8.15(\mathrm{~d}, J=8.2 \mathrm{~Hz}, 1 \mathrm{H}, 9-\mathrm{CH}) .{ }^{13} \mathrm{C} \mathrm{NMR}\left(\mathrm{CDCl}_{3}\right): \delta[\mathrm{ppm}]=20.2(2 \mathrm{C}$, $\left.\mathrm{NCH}_{2} \mathrm{CH}\left(\mathrm{CH}_{3}\right)_{2}\right), 21.3$ (1C, $\left.\mathrm{CH}_{3}\right), 27.8\left(1 \mathrm{C}, \mathrm{NCH}_{2} \mathrm{CH}\left(\mathrm{CH}_{3}\right)_{2}\right), 44.5$ (1C, C-3), $52.6\left(1 \mathrm{C}, \mathrm{CO}_{2} \mathrm{CH}_{3}\right), 56.4$ (1C, $\left.\mathrm{NCH}_{2} \mathrm{CH}\left(\mathrm{CH}_{3}\right)_{2}\right), 127.1$ (2C, $C$-2 tolyl $\left._{1}, C-6_{\text {tolyl }}\right), 128.1$ (1C, C-8), 128.4 (1C, C-6), 129.9 (2C, $C$-3 tolyl,

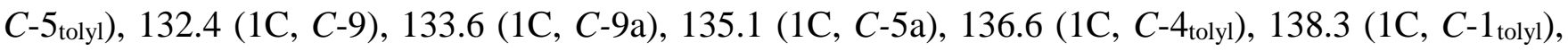
141.9 (1C, C-5), 143.3 (1C, C-7), 166.1 (1C, $\left.\mathrm{CO}_{2} \mathrm{CH}_{3}\right), 168.0$ (1C, C-1). IR (neat): v [ $\left.\mathrm{cm}^{-1}\right]=2937$ (C$\left.\mathrm{H}_{\text {aliph. }}\right), 1727$ ( $\left.\mathrm{C}=\mathrm{O}_{\text {amide }}\right), 1597$ (C=C). 
Mixture of 24a and 24b: As described above, a mixture of the regioisomers 23a and 23b (120 mg, 0.34 mmol) was reacted with 4-methylbenzeneboronic acid (51 mg, $0.37 \mathrm{mmol}$ ). Pale yellow oil, yield $74 \mathrm{mg}$ (60\%). Ratio 24a:24b = 1:1.

\subsubsection{2-Isobutyl- $N$ - $\{4-[N$-methyl- $N$-(tetrahydro-2H-pyran-4-yl)aminomethyl]phenyl $\}-1-0 x 0-8-(p$ - tolyl)-2,3-dihydro-1H-2-benzazepine-4-carboxamide (26a)}

The ester 24a (90 mg, $0.25 \mathrm{mmol})$ was dissolved in $\mathrm{H}_{3} \mathrm{COH}(10 \mathrm{~mL})$ and $5 \mathrm{M} \mathrm{NaOH}(10 \mathrm{~mL})$ was added. The mixture was heated to reflux for $30 \mathrm{~min}$. After cooling down to $0{ }^{\circ} \mathrm{C}$, the mixture was acidified with conc. $\mathrm{HCl}$ to give a precipitate. The aqueous layer was extracted with ethyl acetate $(3 \mathrm{x}$ $25 \mathrm{~mL}$ ), the combined organic layers were dried $\left(\mathrm{Na}_{2} \mathrm{SO}_{4}\right)$, added to the precipitate and concentrated in vacuo to give the acid 25a. Colorless solid, yield $87 \mathrm{mg}(97 \%) . \mathrm{C}_{22} \mathrm{H}_{23} \mathrm{NO}_{3}, \mathrm{M}_{\mathrm{r}}=349.4$. Amine 13 (64 mg, 0.25 mmol, 1 equiv.) was added to a vigorously stirred mixture of acid 25a (87 mg, $0.25 \mathrm{mmol}, 1$ equiv.), trimethylamine (51 mg, 0.5 mmol, 2 equiv.) and HATU (105 mg, 0.28 mmol, 1.1 equiv.) in abs. THF (10 mL). The mixture was stirred overnight at rt. Then the mixture was concentrated in vacuo. Sat. $\mathrm{NaHCO}_{3}$-solution (20 mL) was added to the residue and the mixture was extracted with $\mathrm{CH}_{2} \mathrm{Cl}_{2}(3 \times 20$ $\mathrm{mL}$ ). The combined organic layers were concentrated in vacuo to give a yellow oil, which was first purified by automatic fc (Biotage ${ }^{\circledR}$, SNAP Cartridge KP-C18-HS 30g, water/acetonitrile) to give $26 \mathbf{a}$. Pale yellow solid, yield $54 \mathrm{mg}$ (39\%). Exact MS (APCI): $\mathrm{m} / \mathrm{z}=552.3236$ (calcd. 552.3221 for $\left.\mathrm{C}_{35} \mathrm{H}_{41} \mathrm{~N}_{3} \mathrm{O}_{3}\left[\mathrm{MH}^{+}\right]\right) .{ }^{1} \mathrm{H} \mathrm{NMR}\left(\mathrm{CDCl}_{3}\right): \delta[\mathrm{ppm}]=0.86\left(\mathrm{~d}, J=6.6 \mathrm{~Hz}, 6 \mathrm{H}, \mathrm{NCH}_{2} \mathrm{CH}\left(\mathrm{CH}_{3}\right)_{2}\right), 1.70-$

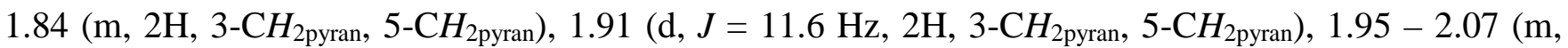
1H, $\left.\mathrm{NCH}_{2} \mathrm{CH}\left(\mathrm{CH}_{3}\right)_{2}\right), 2.36$ (s, 3H, $\mathrm{CH}_{3 \text { tolyl }}$ ), 2.40 (s, 3H, $\mathrm{NCH}_{3}$ ), 3.09 (m, 1H, 4- $\mathrm{CH}_{\text {pyran }}$ ), 3.31 (m, 2H,

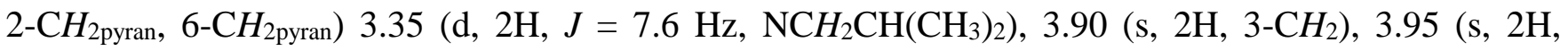
$\mathrm{NCH}_{2}$ ), 4.03 (dd, $J=11.2 / 4.1 \mathrm{~Hz}, 2 \mathrm{H}, 2-\mathrm{CH}_{2 \text { pyran, }}$ 6-CH2pyran), 7.13 (s, 1H, 5-CH), 7.16 (d, $J=8.1 \mathrm{~Hz}$, 2H, 3-CH $\mathrm{CH}_{\text {tolyl, }}$ 5-CH $\left.\mathrm{CH}_{\text {tolyl }}\right), 7.17-7.20$ (m, 1H, 6-CH), 7.35 (d, J = 6.2 Hz, 2H, 2-CH $H_{\text {tolyl, }} 6-\mathrm{CH}_{\text {toly }}$ ), 7.40 (d, 
$J=8.3 \mathrm{~Hz}, 2 \mathrm{H}, 3-\mathrm{CH}_{\text {phenyl, }}$ 5-CH $\left.\mathrm{CH}_{\text {phenl) }}\right), 7.62$ (dd, $\left.J=8.2 / 1.8 \mathrm{~Hz}, 1 \mathrm{H}, 7-\mathrm{CH}\right), 7.82$ (d, $J=8.2 \mathrm{~Hz}, 2 \mathrm{H}, 2-$ $\mathrm{CH}_{\text {phenyl, }}$ 6- $\left.\mathrm{CH}_{\text {phenyl }}\right), 8.08(\mathrm{~s}, 1 \mathrm{H}, 9-\mathrm{CH}), 9.62(\mathrm{~s}, 1 \mathrm{H}, \mathrm{NH}) .{ }^{13} \mathrm{C} \mathrm{NMR}\left(\mathrm{CDCl}_{3}\right): \delta[\mathrm{ppm}]=20.2(2 \mathrm{C}$, NCH$\left.{ }_{2} \mathrm{CH}\left(\mathrm{CH}_{3}\right)_{2}\right), 21.3$ (1C, $\left.\mathrm{CH}_{3 \text { tolyl }}\right), 27.7$ (1C, $\left.\mathrm{NCH}_{2} \mathrm{CH}\left(\mathrm{CH}_{3}\right)_{2}\right), 27.9$ (2C, $C-3_{\text {pyran, }}$ - $\left.-5_{\text {pyran}}\right), 35.9$ (1C, $\mathrm{NCH}_{3}$ ), $44.6\left(1 \mathrm{C}, \mathrm{PhCH}_{2} \mathrm{~N}\right), 56.23$ (1C NCH $\left.\mathrm{CH}_{2}\left(\mathrm{CH}_{3}\right)_{2}\right)$, 56.5 (1C, C-3), 59.5 (1C, C-4 pyran), 67.0 (2C, $\left.C-2_{\text {pyran}}, C-6_{\text {pyran }}\right), 120.6$ (2C, $\left.C-2_{\text {phenyl }}, C-6_{\text {phenyl }}\right), 126.9$ (2C, $\left.C-2_{\text {tolyl }}, C-6_{\text {tolyl }}\right), 127.0$ (1C, C-7), 127.1 (1C, C-5), 127.2 (1C, C-5a), 127.4 (1C, C-6), 129.2 (1C, C-4 phenyl), 129.7 (1C. C-1 tolyl), 129.8 (2C, C-

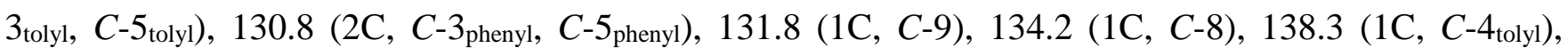

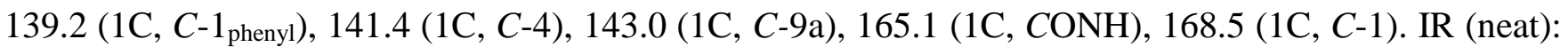
$v\left[\mathrm{~cm}^{-1}\right]=2937\left(\mathrm{C}-\mathrm{H}_{\text {aliph. }}\right), 1727\left(\mathrm{C}=\mathrm{O}_{\text {amide }}\right), 1600(\mathrm{C}=\mathrm{C})$. HPLC (method 1): $\mathrm{t}_{\mathrm{R}}=21.51$ min, purity 98.3\%.

\subsubsection{2-Isobutyl- $N$-\{4-[N-methyl- $N$-(tetrahydro-2H-pyran-4-yl)aminomethyl]phenyl\}-1-oxo-7-(p- tolyl)-2,3-dihydro-1H-2-benzazepine-4-carboxamide (26b)}

The ester 24b (82 mg, $0.23 \mathrm{mmol})$ was dissolved in $\mathrm{H}_{3} \mathrm{COH}(10 \mathrm{~mL})$ and $5 \mathrm{M} \mathrm{NaOH}(10 \mathrm{~mL})$ was added. The mixture was heated to reflux for $30 \mathrm{~min}$. After cooling down to $0{ }^{\circ} \mathrm{C}$, the mixture was acidified with conc. $\mathrm{HCl}$ to give a precipitate. The aqueous layer was extracted with EtOAc (3 x $25 \mathrm{~mL})$, the combined organic layers were dried $\left(\mathrm{Na}_{2} \mathrm{SO}_{4}\right)$, added to the precipitate and concentrated in vacuo to give the acid 25b. Colorless solid, yield $79 \mathrm{mg}$ (97\%). $\mathrm{C}_{22} \mathrm{H}_{23} \mathrm{NO}_{3} \mathrm{M}_{\mathrm{r}}=349.4 \mathrm{~g} / \mathrm{mol}$. Amine 13 (58 mg, $0.23 \mathrm{mmol}$ ) was added to a vigorously stirred mixture of acid $25 \mathbf{b}$ (79 $\mathrm{mg}, 0.23 \mathrm{mmol}$ ), triethylamine (46 mg, $0.45 \mathrm{mmol}$ ) and HATU (95 mg, $0.25 \mathrm{mmol}$ ) in THF (10 mL). The mixture was stirred overnight at rt. Then the mixture was concentrated in vacuo. Saturated $\mathrm{NaHCO}_{3}$ solution $(20 \mathrm{~mL})$ was added to the residue and the mixture was extracted with $\mathrm{CH}_{2} \mathrm{Cl}_{2}(3 \times 20 \mathrm{~mL})$. The combined organic layers were concentrated in vacuo to give a yellow oil, which was purified by automatic fc (Biotage ${ }^{\circledR}$, SNAP KPC18-HS 30 g, water/acetonitrile) to give 26b. Pale yellow solid, yield 42 mg (34\%). $\mathrm{C}_{35} \mathrm{H}_{41} \mathrm{~N}_{3} \mathrm{O}_{3}$, 
$\mathrm{M}_{\mathrm{r}}=551.7$. Exact MS (APCI): $\mathrm{m} / \mathrm{z}=552.3236$ (calcd. 552.3221 for $\mathrm{C}_{35} \mathrm{H}_{41} \mathrm{~N}_{3} \mathrm{O}_{3}\left[\mathrm{MH}^{+}\right]$). ${ }^{1} \mathrm{H} \mathrm{NMR}$ $\left(\mathrm{CDCl}_{3}\right): \delta[\mathrm{ppm}]=0.88\left(\mathrm{~d}, J=6.7 \mathrm{~Hz}, 6 \mathrm{H}, \mathrm{NCH}_{2} \mathrm{CH}\left(\mathrm{CH}_{3}\right)_{2}\right), 1.72-1.79\left(\mathrm{~m}, 2 \mathrm{H}, 3-\mathrm{CH}_{2 \text { pyran}}, 5-\right.$

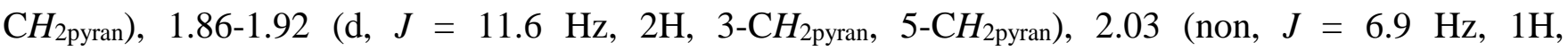
$\left.\mathrm{NCH}_{2} \mathrm{CH}\left(\mathrm{CH}_{3}\right)_{2}\right), 2.36$ (s, 3H, $\left.\mathrm{NCH}_{3}\right), 2.40$ (s, 3H, $\left.\mathrm{CH}_{3 \text { tolyl }}\right), 2.89$ - 3.02 (m, 1H, 4-CH pyran$_{\text {) }} 3.30$ - 3.37

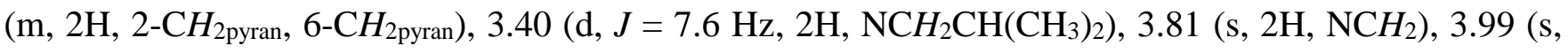

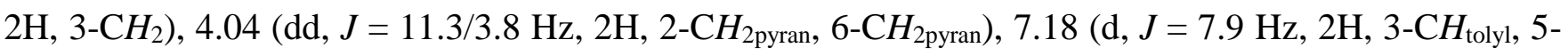
$\left.\mathrm{CH}_{\text {tolyl }}\right), 7.25$ (m, 1H, 6-CH), 7.38 (m, 3H, 5-CH, 2- $\mathrm{CH}_{\text {phenyl }}$ 6-CHphenyl), 7.42 (d, J = 8.1 Hz, 2H, 3$\mathrm{CH}_{\text {phenyl, }}$ 5- $\left.\mathrm{CH}_{\text {phenyl }}\right), 7.64$ (dd, $\left.J=8.2 / 1.8 \mathrm{~Hz}, 1 \mathrm{H}, 8-\mathrm{CH}\right), 7.78$ (d, $J=8.3 \mathrm{~Hz}, 2 \mathrm{H}, 2-\mathrm{CH} H_{\text {phenyl, }}$ 6$\left.\mathrm{CH}_{\text {phenyl }}\right), 8.10$ (d, $\left.J=8.2 \mathrm{~Hz}, 1 \mathrm{H}, 9-\mathrm{CH}\right), 9.23$ (s, $\left.1 \mathrm{H}, \mathrm{NH}\right) .{ }^{13} \mathrm{C} \mathrm{NMR}\left(\mathrm{CDCl}_{3}\right): \delta[\mathrm{ppm}]=20.2(2 \mathrm{C}$, $\left.\mathrm{NCH}_{2} \mathrm{CH}\left(\mathrm{CH}_{3}\right)_{2}\right), 21.3$ (1C, $\left.\mathrm{CH}_{3 \text { tolyl }}\right), 27.7$ (1C, $\left.\mathrm{NCH}_{2} \mathrm{CH}\left(\mathrm{CH}_{3}\right)_{2}\right), 28.3$ (2C, $\left.C-3_{\text {pyran }}, C-5_{\text {pyran }}\right), 36.5$ (1C, $\mathrm{NCH}_{3}$ ), 44.7 (1C, C-3), 56.2 (1C NCH $\left.2 \mathrm{CH}\left(\mathrm{CH}_{3}\right)_{2}\right), 56.9$ (1C, $\left.\mathrm{PhCH}_{2} \mathrm{~N}\right), 59.7$ (1C, C-4 pyran), 67.3 (2C, C2pyran, $\left.C-6_{\text {pyran }}\right), 120.5$ (2C, $\left.C-2_{\text {phenyl }}, C-6_{\text {phenyl }}\right), 127.0$ (2C, $\left.C-2_{\text {tolyl }}, C-6_{\text {tolyl }}\right), 127.3$ (1C, C-6), 127.5 (1C,

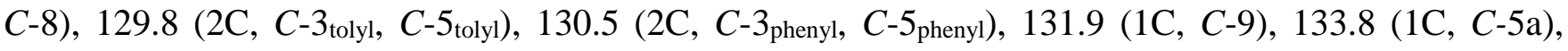

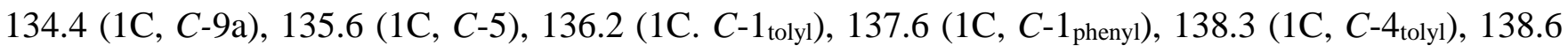
(1C, C-4 $4_{\text {phenyl }}$ ), 143.1 (1C, C-7), 165.0 (1C, CONH), 168.4 (1C, C-1). IR (neat): v [cm $\left.{ }^{-1}\right]=2937$ (C-

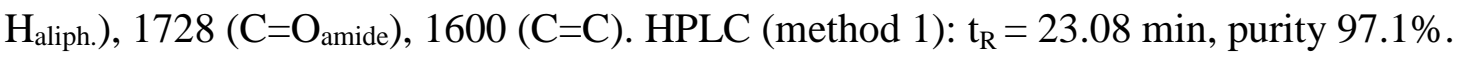

Separation of regioisomeric 26a and 26b: As described above, a mixture of the regioisomers 24a and 24b (74 mg, $0.2 \mathrm{mmol})$ was reacted with $5 \mathrm{M} \mathrm{NaOH}(5 \mathrm{~mL})$ and the resulting mixture of acids 25a and 25b was subsequently coupled with primary amine 13 (51 mg, $0.2 \mathrm{mmol}$ ) and HATU (83 mg, 0.22 mmol). Pale yellow oil, yield $51 \mathrm{mg}$ (46\%). The 1:1-mixture of regioisomers 26a and 26b was separated by preparative HPLC (method 2, acetonitrile : $\mathrm{H}_{2} \mathrm{O}=$ 70:30, 60 min per run). 26a: Colorless solid, yield 12 mg (24\%). 26b: Colorless solid, yield 16 mg (31\%). 


\subsubsection{Methyl 2-isobutyl-8-nitro-1-oxo-2,3-dihydro-1H-2-benzazepine-4-carboxylate (27a) and Methyl 2-isobutyl-6-nitro-1-oxo-2,3-dihydro-1H-2-benzazepine-4-carboxylate (27c)}

Concentrated $\mathrm{H}_{2} \mathrm{SO}_{4}(1.04 \mathrm{~mL})$ was added slowly, with ice-water cooling and stirring, to $100 \% \mathrm{HNO}_{3}$ (1.04 mL). 11 (280 mg, $1.02 \mathrm{mmol}, 1$ equiv.) was dissolved in nitromethane (0.5 mL) and cooled to $0{ }^{\circ} \mathrm{C}$. After nitrating acid was added slowly at this temperature, the solution was warmed to rt and stirred for $2 \mathrm{~h}$. Then ice-water was poured into the reaction mixture, neutralized with $3 \mathrm{M} \mathrm{NaOH}(10 \mathrm{~mL})$ and extracted with $\mathrm{CH}_{2} \mathrm{Cl}_{2}(2 \times 15 \mathrm{~mL})$ and ethyl acetate $(2 \times 15 \mathrm{~mL})$. The combined organic layers were dried $\left(\mathrm{Na}_{2} \mathrm{SO}_{4}\right)$ and concentrated in vacuo. The residue was purified by fc $(\varnothing=3 \mathrm{~cm}, \mathrm{~h}=17 \mathrm{~cm}$, cyclohexane / ethyl acetate $=7: 2, \mathrm{~V}=20 \mathrm{~mL}, \mathrm{R}_{\mathrm{f}}=0.02($ cyclohexane $/$ ethyl acetate $=7: 2)$ ) to give a mixture of regioisomers 27a and 27c. Pale yellow oil, yield 273 mg (83\%). $\mathrm{C}_{16} \mathrm{H}_{18} \mathrm{~N}_{2} \mathrm{O}_{5}$, $\mathrm{M}_{\mathrm{r}}=$ 318.3. Ratio of 27a:27c $=7: 3$. Exact mass (ESI): $\mathrm{m} / \mathrm{z}=341.1109$ (calcd. 341.1108 for $\left.\mathrm{C}_{16} \mathrm{H}_{18} \mathrm{~N}_{2} \mathrm{NaO}_{5}\left[\mathrm{MNa}^{+}\right]\right)$. IR (neat): $v\left[\mathrm{~cm}^{-1}\right]=2959\left(\mathrm{C}-\mathrm{H}_{\text {alkyl }}\right), 1713(\mathrm{C}=\mathrm{O}), 1636(\mathrm{NC}=\mathrm{O}), 1524(\mathrm{~N}=\mathrm{O})$, 1346 ( $\mathrm{NO}_{2}$ arom.). HPLC (method 1): $\mathrm{t}_{\mathrm{R}}=20.43 \mathrm{~min}$, purity 97.7\%. The two regioisomers were separated by fc $\left(\varnothing=2.5 \mathrm{~cm}, \mathrm{~h}=24 \mathrm{~cm}, \mathrm{CH}_{2} \mathrm{Cl}_{2}\right.$ : ethyl acetate $\left.=95: 5, \mathrm{~V}=20 \mathrm{~mL}\right)$ to give $27 \mathbf{a}$ and $27 \mathrm{c}$.

27a $\left(\mathrm{R}_{\mathrm{f}}=0.38, \mathrm{CH}_{2} \mathrm{Cl}_{2}\right.$ : ethyl acetate = 95 : 5): Pale yellow solid, mp $109{ }^{\circ} \mathrm{C}$, yield $178 \mathrm{mg}(54 \%)$. $\mathrm{C}_{16} \mathrm{H}_{18} \mathrm{~N}_{2} \mathrm{O}_{5}, \quad \mathrm{M}_{\mathrm{r}}=318.3$. Exact mass (ESI): $\mathrm{m} / \mathrm{z}=341.1106$ (calcd. 341.1108 for $\mathrm{C}_{16} \mathrm{H}_{18} \mathrm{~N}_{2} \mathrm{NaO}_{5}$ $\left.\left[\mathrm{MNa}^{+}\right]\right) .{ }^{1} \mathrm{H} \mathrm{NMR}\left(\mathrm{CDCl}_{3}\right): \delta[\mathrm{ppm}]=0.94\left(\mathrm{~d}, J=6.7 \mathrm{~Hz}, 6 \mathrm{H}, \mathrm{NCH}_{2} \mathrm{CH}\left(\mathrm{CH}_{3}\right)_{2}\right), 2.14-2.21(\mathrm{~m}, 1 \mathrm{H}$, $\left.\mathrm{NCH}_{2} \mathrm{CH}\left(\mathrm{CH}_{3}\right)_{2}\right), 3.45$ (d, $\left.J=7.6 \mathrm{~Hz}, 2 \mathrm{H}, \mathrm{NCH}_{2} \mathrm{CH}\left(\mathrm{CH}_{3}\right)_{2}\right), 3.91$ (s, 3H, $\left.\mathrm{CO}_{2} \mathrm{CH}_{3}\right), 4.02$ (s, 2H, 3-CH2), 7.53 (d, $J=8.5 \mathrm{~Hz}, 1 \mathrm{H}, 6-\mathrm{CH}), 7.84$ (s, 1H, 5-CH), 8.30 (dd, $J=8.5 / 2.4 \mathrm{~Hz}, 1 \mathrm{H}, 7-\mathrm{CH}), 8.92$ (d, $J=2.0$

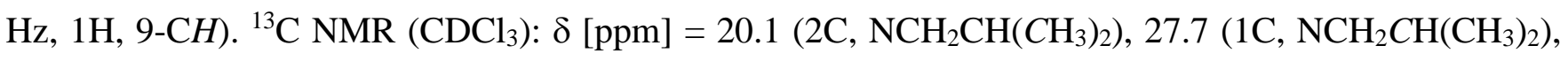
44.2 (1C, C-3), 53.0 (1C, $\mathrm{CO}_{2} \mathrm{CH}_{3}$ ), 56.6 (1C, $\left.\mathrm{NCH}_{2} \mathrm{CH}\left(\mathrm{CH}_{3}\right)_{2}\right), 124.8$ (1C, C-7), 127.3 (1C, C-9), 130.9 (1C, C-6), 136.0 (1C, C-4), 138.2 (1C, C-9a), 138.4 (1C, C-5a), 139.2 (1C, C-5), 148.3 (1C, C-8), 165.4 (1C, $\left.\mathrm{CO}_{2} \mathrm{CH}_{3}\right), 166.2$ (1C, C-1). FT-IR (neat): v [ $\left.\mathrm{cm}^{-1}\right]=2963\left(\mathrm{C}-\mathrm{H}_{\mathrm{alkyl}}\right), 1709(\mathrm{C}=\mathrm{O}), 1632(\mathrm{NC}=\mathrm{O})$, $1520(\mathrm{~N}=\mathrm{O}), 1354\left(\mathrm{NO}_{2}\right.$ arom.). HPLC (method 1): $\mathrm{t}_{\mathrm{R}}=20.81 \mathrm{~min}$, purity 96.5\%. 
27c $\left(\mathrm{R}_{\mathrm{f}}=0.24, \mathrm{CH}_{2} \mathrm{Cl}_{2}\right.$ : ethyl acetate = 95 : 5): Pale yellow oil, yield 29 mg (9\%). $\mathrm{C}_{16} \mathrm{H}_{18} \mathrm{~N}_{2} \mathrm{O}_{5}$, $\mathrm{M}_{\mathrm{r}}=$ 318.3. Exact mass (ESI): $\mathrm{m} / \mathrm{z}=341.1116$ (calcd. 341.1108 for $\mathrm{C}_{16} \mathrm{H}_{18} \mathrm{~N}_{2} \mathrm{NaO}_{5}\left[\mathrm{MNa}^{+}\right]$). ${ }^{1} \mathrm{H} \mathrm{NMR}$

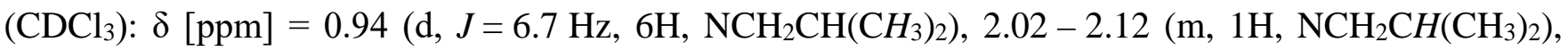
$3.44\left(\mathrm{~d}, J=6.2 \mathrm{~Hz}, 2 \mathrm{H}, \mathrm{NCH}_{2} \mathrm{CH}\left(\mathrm{CH}_{3}\right)_{2}\right), 3.89$ (s, 3H, $\left.\mathrm{CO}_{2} \mathrm{CH}_{3}\right), 4.00\left(\mathrm{~s}, 2 \mathrm{H}, 3-\mathrm{CH}_{2}\right), 7.63(\mathrm{t}, J=$ $8.0 \mathrm{~Hz}, 1 \mathrm{H}, 8-\mathrm{CH}$ ), 7.96 (s, 1H, 5-CH), 8.10 (dd, $J=8.1 / 1.4 \mathrm{~Hz}, 1 \mathrm{H}, 7-\mathrm{CH}$ ), 8.31 (dd, $J=7.9 / 1.3 \mathrm{~Hz}$, 1H, 9-CH). ${ }^{13} \mathrm{C} \mathrm{NMR}\left(\mathrm{CDCl}_{3}\right): \delta[\mathrm{ppm}]=20.1\left(2 \mathrm{C}, \mathrm{NCH}_{2} \mathrm{CH}\left(\mathrm{CH}_{3}\right)_{2}\right), 27.6\left(1 \mathrm{C}, \mathrm{NCH}_{2} \mathrm{CH}\left(\mathrm{CH}_{3}\right)_{2}\right), 43.8$ (1C, $C$-3), 53.0 (1C, $\mathrm{CO}_{2} \mathrm{CH}_{3}$ ), 56.2 (1C, $\left.\mathrm{NCH}_{2} \mathrm{CH}\left(\mathrm{CH}_{3}\right)_{2}\right), 126.7$ (1C, C-7), 127.2 (1C, C-5a), 129.9 (1C, C-8), 134.6 (1C, C-4), 134.9 (1C, C-5), 136.2 (1C, C-9), 139.2 (1C, C-9a), 148.3 (1C, C-6), 165.6 (1C, $\left.\mathrm{CO}_{2} \mathrm{CH}_{3}\right), 166.3(1 \mathrm{C}, \mathrm{C}-1)$. IR (neat): $v\left[\mathrm{~cm}^{-1}\right]=2959\left(\mathrm{C}-\mathrm{H}_{\mathrm{alky}}\right), 1712(\mathrm{C}=\mathrm{O}), 1636(\mathrm{NC}=\mathrm{O}), 1528$ $(\mathrm{N}=\mathrm{O}), 1343\left(\mathrm{NO}_{2}\right.$ arom.). HPLC (method 1): $\mathrm{t}_{\mathrm{R}}=20.81 \mathrm{~min}$, purity 92.9\%.

\subsubsection{2-Isobutyl- $N$ - $\{4-[N$-methyl- $N$-(tetrahydro-2H-pyran-4-yl)aminomethyl]phenyl\}-8-nitro-1-} oxo-2,3-dihydro-1H-2-benzazepine-4-carboxamide (29a) and

2-Isobutyl- $N$-\{4-[N-methyl- $N$-(tetrahydro-2H-pyran-4-yl)aminomethyl]phenyl\}-6-nitro-1-oxo-2,3dihydro-1H-2-benzazepine-4-carboxamide (29c)

Amine 13 (193 mg, 0.66 mmol, 1 equiv.) was added to a vigorously stirred mixture of the regioisomeric acids 28a and 28c (200 mg, 0.66 mmol, 1 equiv.), NEt3 (182 $\mu \mathrm{L}, 133 \mathrm{mg}, 1.32 \mathrm{mmol}, 2$ equiv.) and HATU (275 mg, $0.72 \mathrm{mmol}, 1.1$ equiv.) in abs. THF (8 mL). The mixture was stirred overnight at rt. After further addition of $\mathrm{NEt}_{3}$ (133 mg, $1.32 \mathrm{mmol}, 2$ equiv.) and HATU (274.9 mg, $0.72 \mathrm{mmol}$, 1.1 equiv.) the mixture was stirred for $3 \mathrm{~h}$. The solvent was removed in vacuo and saturated $\mathrm{NaHCO}_{3}{ }^{-}$ solution $(25 \mathrm{~mL})$ was added to the residue. The mixture was extracted with ethyl acetate $(3 \times 30 \mathrm{~mL})$. The combined organic layers were dried $\left(\mathrm{Na}_{2} \mathrm{SO}_{4}\right)$ and concentrated in vacuo to give the amides 29a and 29c as a light brown oil as mixture of regioisomers. This was purified and separated by fc $(\varnothing=2.5 \mathrm{~cm}$, $\mathrm{h}=17 \mathrm{~cm}, \mathrm{CH}_{2} \mathrm{Cl}_{2}: \mathrm{H}_{3} \mathrm{COH}=96: 4+1 \% \mathrm{NH}_{3}, \mathrm{~V}=20 \mathrm{~mL}$ ) to give the pure amides 29a and 29c, and a 
fraction containing a mixture, which was further separated by another fc $\left(\varnothing=1 \mathrm{~cm}, \mathrm{~h}=17 \mathrm{~cm}, \mathrm{CH}_{2} \mathrm{Cl}_{2}\right.$ : $\left.\mathrm{H}_{3} \mathrm{COH}=97: 3+1 \% \mathrm{NH}_{3}, \mathrm{~V}=5 \mathrm{~mL}\right)$.

29a $\left(\mathrm{R}_{\mathrm{f}}=0.28, \mathrm{CH}_{2} \mathrm{Cl}_{2}: \mathrm{H}_{3} \mathrm{COH}=95: 5+1 \% \mathrm{NH}_{3}\right)$. Yellow solid, mp $200{ }^{\circ} \mathrm{C}$, yield $32 \mathrm{mg}(9 \%)$. $\mathrm{C}_{28} \mathrm{H}_{34} \mathrm{~N}_{4} \mathrm{O}_{5}, \mathrm{M}_{\mathrm{r}}=506.6$. Exact mass (ESI): $\mathrm{m} / \mathrm{z}=507.2595$ (calcd. 507.2602 for $\mathrm{C}_{28} \mathrm{H}_{35} \mathrm{~N}_{4} \mathrm{O}_{5}\left[\mathrm{MH}^{+}\right]$). ${ }^{1} \mathrm{H}$ NMR $\left(\mathrm{CDCl}_{3}\right): \delta[\mathrm{ppm}]=0.89\left(\mathrm{~d}, J=6.6 \mathrm{~Hz}, 6 \mathrm{H}, \mathrm{NCH}_{2} \mathrm{CH}\left(\mathrm{CH}_{3}\right)_{2}\right), 1.67-1.84\left(\mathrm{~m}, 4 \mathrm{H}, 3-\mathrm{CH}_{\text {pyran}}\right.$,

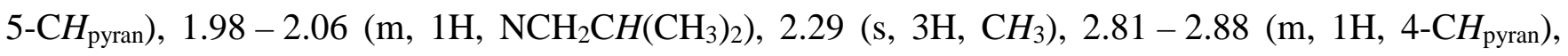
$3.31-3.36$ (m, 2H, 2- $\mathrm{CH}_{\text {pyran, }}$ 6- $\mathrm{CH}_{\text {pyran }}$ ), 3.40 (d, $\left.J=7.6 \mathrm{~Hz}, 2 \mathrm{H}, \mathrm{NCH}_{2} \mathrm{CH}\left(\mathrm{CH}_{3}\right)_{2}\right), 3.72$ (s, $\left.2 \mathrm{H}, \mathrm{CH}_{2} \mathrm{~N}\right)$, 3.99 (s, 2H, 3- $\left.\mathrm{CH}_{2}\right), 4.02-4.06$ (m, 2H, 2- $\mathrm{CH}_{\text {pyran, 6-CH }}$ pyran), 7.28 (d, J = $\left.8.5 \mathrm{~Hz}, 1 \mathrm{H}, 6-\mathrm{CH}\right), 7.36$ (d, $\left.J=8.4 \mathrm{~Hz}, 2 \mathrm{H}, 3-\mathrm{CH}_{\text {aniline, 5-CH }} \mathrm{CH}_{\text {anine}}\right), 7.38$ (s, 1H, 5-CH), 7.68 (d, $J=8.4 \mathrm{~Hz}, 2 \mathrm{H}, 2-\mathrm{CH}_{\text {aniline, }}$ 6CHaniline), 8.18 (dd, $J=8.5 / 2.4 \mathrm{~Hz}, 1 \mathrm{H}, 7-\mathrm{CH}), 8.86$ (d, $J=2.4 \mathrm{~Hz}, 1 \mathrm{H}, 9-\mathrm{CH}), 9.01$ (s, $1 \mathrm{H}, \mathrm{NH}) .{ }^{13} \mathrm{C}$ NMR $\left(\mathrm{CDCl}_{3}\right): \delta[\mathrm{ppm}]=20.1\left(2 \mathrm{C}, \mathrm{NCH}_{2} \mathrm{CH}\left(\mathrm{CH}_{3}\right)_{2}\right), 27.7\left(1 \mathrm{C}, \mathrm{NCH}_{2} \mathrm{CH}\left(\mathrm{CH}_{3}\right)_{2}\right), 28.6\left(2 \mathrm{C}, C-3_{\text {pyran, }} C-\right.$ 5pyran), 36.8 (1C, $\left.\mathrm{CH}_{3}\right), 44.5$ (1C, $\left.C-3\right), 56.4$ (1C, $\left.\mathrm{NCH}_{2} \mathrm{CH}\left(\mathrm{CH}_{3}\right)_{2}\right), 56.9$ (1C, $\left.\mathrm{CH}_{2} \mathrm{~N}\right), 59.5$ (1C, C-4 pyran),

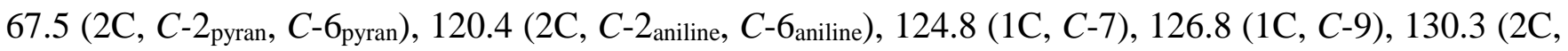

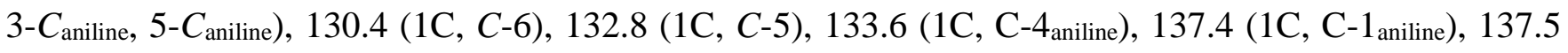
(1C, C-9a), 138.6 (1C, C-5a), 140.8 (1C, C-4), 147.8 (1C, C-8), 164.0 (1C, CONH), 166.5 (1C, C-1). IR (neat): $v\left[\mathrm{~cm}^{-1}\right]=3267(\mathrm{~N}-\mathrm{H}), 2920\left(\mathrm{C}-\mathrm{H}_{\mathrm{alkyl}}\right), 1632(\mathrm{C}=\mathrm{O}), 1520(\mathrm{~N}=\mathrm{O}), 1343\left(\mathrm{NO}_{2}\right.$ arom.). HPLC (method 1): $\mathrm{t}_{\mathrm{R}}=17.43$ min, purity $97.3 \%$.

29c $\left(\mathrm{R}_{\mathrm{f}}=0.32, \mathrm{CH}_{2} \mathrm{Cl}_{2}: \mathrm{H}_{3} \mathrm{COH}=95: 5+1 \% \mathrm{NH}_{3}\right)$. Pale yellow solid, mp $197{ }^{\circ} \mathrm{C}$, yield $45.6 \mathrm{mg}$ (14\%). $\mathrm{C}_{28} \mathrm{H}_{34} \mathrm{~N}_{4} \mathrm{O}_{5}, \mathrm{M}_{\mathrm{r}}=$ 506.6. Exact mass (ESI): $m / z=507.2595$ (calcd. 507.2602 for $\mathrm{C}_{28} \mathrm{H}_{35} \mathrm{~N}_{4} \mathrm{O}_{5}$ $\left.\left[\mathrm{MH}^{+}\right]\right) .{ }^{1} \mathrm{H} \mathrm{NMR}\left(\mathrm{CDCl}_{3}\right): \delta[\mathrm{ppm}]=0.87\left(\mathrm{~d}, J=6.6 \mathrm{~Hz}, 6 \mathrm{H}, \mathrm{NCH}_{2} \mathrm{CH}\left(\mathrm{CH}_{3}\right)_{2}\right), 1.64-1.79(\mathrm{~m}, 4 \mathrm{H}, 3-$ $\mathrm{CH}_{\text {pyran, }}$ 5- $\left.\mathrm{CH}_{\text {pyran}}\right), 1.94-2.05\left(\mathrm{~m}, 1 \mathrm{H}, \mathrm{NCH}_{2} \mathrm{CH}\left(\mathrm{CH}_{3}\right)_{2}\right), 2.22$ (s, 3H, $\left.\mathrm{CH}_{3}\right), 2.62-2.70(\mathrm{~m}, 1 \mathrm{H}$, 4- $\left.\mathrm{CH}_{\text {pyran }}\right), 3.33-3.40\left(\mathrm{~m}, 4 \mathrm{H}, \mathrm{NCH}_{2} \mathrm{CH}\left(\mathrm{CH}_{3}\right)_{2}, 2-\mathrm{CH}_{\text {pyran, }}\right.$ 6- $\left.\mathrm{CH}_{\text {pyran }}\right), 3.60\left(\mathrm{~s}, 2 \mathrm{H}, \mathrm{CH}_{2} \mathrm{~N}\right), 3.89-4.06$

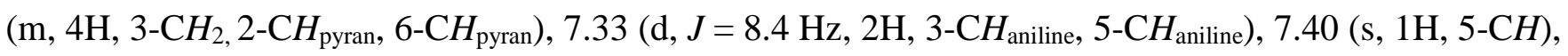
7.56 (t, $J=8.0 \mathrm{~Hz}, 1 \mathrm{H}, 8-\mathrm{CH}), 7.69$ (d, $J=8.5 \mathrm{~Hz}, 2 \mathrm{H}, 2-\mathrm{CH}_{\text {aniline, }}$ 6-CHaniline), 8.04 (dd, $J=8.1 / 1.4 \mathrm{~Hz}$, 
1H, 7-CH), 8.25 (dd, $J=7.9 / 1.3 \mathrm{~Hz}, 1 \mathrm{H}, 9-\mathrm{CH}$ ). A signal for the $\mathrm{NH}$ proton is not seen in the spectrum. ${ }^{13} \mathrm{C} \mathrm{NMR}\left(\mathrm{CDCl}_{3}\right): \delta[\mathrm{ppm}]=19.9\left(2 \mathrm{C}, \mathrm{NCH}_{2} \mathrm{CH}\left(\mathrm{CH}_{3}\right)_{2}\right), 27.5\left(1 \mathrm{C}, \mathrm{NCH}_{2} \mathrm{CH}\left(\mathrm{CH}_{3}\right)_{2}\right), 29.1(2 \mathrm{C}, \mathrm{C}-$

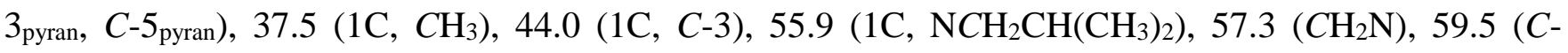
4 pyran), 67.6 (2C, $\left.C-2_{\text {pyran }}, C-6_{\text {pyran}}\right), 120.2$ (2C, $\left.C-2_{\text {aniline, }} C-6_{\text {aniline }}\right), 126.9$ (1C, $\left.C-7\right), 127.3$ (1C, $\left.C-5 a\right)$, 128.2 (1C, C-5), 129.4 (2C, C-3aniline, $C$-5aniline), 129.5 (1C, C-8), 135.8 (1C, C-9), 136.1 (1C, $C-1_{\text {aniline), }}$ ) 136.8 (1C, C-4aniline), 138.5 (1C, C-9a), 139.3 (1C, C-4), 147.2 (1C, C-6), 164.0 (1C, CONH), 166.3 (1C, $C$-1). IR (neat): $v\left[\mathrm{~cm}^{-1}\right]=3291(\mathrm{~N}-\mathrm{H}), 2955\left(\mathrm{C}-\mathrm{H}_{\text {alkyl }}\right), 1628(\mathrm{C}=\mathrm{O}), 1524(\mathrm{~N}=\mathrm{O}), 1343\left(\mathrm{NO}_{2 \text { arom. }}\right)$. HPLC (method 1): $t_{R}=17.13$ min, purity $98.4 \%$.

\subsection{Biological evaluation}

\subsubsection{Affinity towards CCR2 receptors}

Chemicals and reagents

$\left[{ }^{3} \mathrm{H}\right]$ INCB3344 (32 Ci/mmol) was purchased from ViTrax (Placentia, USA - custom synthesis). BMS22 was purchased from Tocris Bioscience (Bristol, UK)

Cell culture and membrane preparation

U2OS cells stably expressing the human CCR2 receptor (Invitrogen, Carlsbad, CA) were cultured in McCoys5a medium supplemented with $10 \%$ fetal calf serum, $2 \mathrm{mM}$ glutamine, $0.1 \mathrm{mM}$ non-essential amino acids (NEAAs), 25 mM 4-(2-hydroxyethyl)piperazine-1-ethanesulfonic acid (HEPES), $1 \mathrm{mM}$ sodium pyruvate, $100 \mathrm{IU} / \mathrm{mL}$ penicillin, $100 \mu \mathrm{g} / \mathrm{mL}$ streptomycin, $100 \mu \mathrm{g} / \mathrm{mL}$ G418, $50 \mu \mathrm{g} / \mathrm{mL}$ hygromycin, and $125 \mu \mathrm{g} / \mathrm{mL}$ zeocin in a humidified atmosphere at $37{ }^{\circ} \mathrm{C}$ and $5 \% \mathrm{CO}_{2}$. Cell culture and membrane preparation were performed as described previously. ${ }^{18}$

\section{$\left[{ }^{3} \mathrm{H}\right]$ INCB3344 binding assays}

Binding assays were performed in a $100 \mu \mathrm{L}$ reaction volume containing $50 \mathrm{mM}$ Tris-HCl buffer (pH 7.4), $5 \mathrm{mM} \mathrm{MgCl}$, 0.1\% 3-[(3-cholamidopropyl)-dimethylammonio]-1-propanesulfonic acid (CHAPS) 
and $20 \mu \mathrm{g}$ of membrane protein at $25^{\circ} \mathrm{C}$. Nonspecific binding was determined with $10 \mu \mathrm{M}$ BMS22. Displacement assays were performed with $7 \mathrm{nM}\left[{ }^{3} \mathrm{H}\right] \mathrm{INCB} 3344$ using at least 6 concentrations of competing ligand for 120 minutes of incubation. The HP D300 digital dispenser from Tecan (Männedorf, Switzerland) was used to dispense the compounds in DMSO directly into the assay plate. Incubations were terminated by dilution with ice-cold $50 \mathrm{mM}$ Tris-HCl buffer supplemented with 0.05\% CHAPS. Separation of bound from free radioligand was performed by rapid filtration through a 96-well GF/B filter plate using a PerkinElmer Filtermate-harvester (PerkinElmer, Groningen, The Netherlands). Filters were washed 10 times with ice-cold wash buffer, and $25 \mu \mathrm{L}$ of Microscint scintillation cocktail (PerkinElmer) was added to each well; the filter-bound radioactivity was determined by scintillation spectrometry using the P-E 1450 Microbeta Wallac Trilux scintillation counter (PerkinElmer).

Data analysis

All experiments were analysed using the nonlinear regression curve fitting program Prism 5 (GraphPad, San Diego, CA).

\subsection{2. $\mathrm{Ca}^{2+}$ flux assay at $\mathrm{CCR} 2$ receptors}

\section{Cell culture}

Chem-1 cell line transfected with human CCR2 (ChemiSCREEN" ${ }^{\mathrm{TM}}$ CCR2B Calcium-Optimized FLIPR Cell Line, Merck Millipore) was used for the intracellular calcium flux assay. U2OS $\beta$-arrestin cell line transfected with murine CCR2 (93-0543C3, DiscoveRx Corporation, Ltd.) was used for the $\beta$-arrestin recruitment assay.

Measurement of intracellular calcium flux ( $G_{q}$ signaling pathway)

Chem-1 cells transfected with human CCR2 were cultured in DMEM high glucose medium (supplemented by 10\% FCS, 1 mM pyruvate, 15 mM HEPES, $500 \mu \mathrm{g} / \mathrm{mL}$ geniticine and non-essential 
amino acids (NEAA)). The cells were transferred into Optimem (supplemented by 5\% FCS, 50 U/mL penicillin and $50 \mu \mathrm{g} / \mathrm{mL}$ streptomycine and NEAA) and seeded into 384-well plates ( $\mu$ CLEAR/black Greiner Bio One) at a density of 5000 cells/25 $\mu \mathrm{L}$. Cells were incubated for approximately $24 \mathrm{~h}$ at 37 ${ }^{\circ} \mathrm{C}, 5 \% \mathrm{CO}_{2}$. Before the assay medium was removed and the cells were incubated with Fluo-4 solution (25 $\mu \mathrm{L}$ Tyrode's solution containing $3 \mu \mathrm{M}$ Fluo-4 AM (1 mM DMSO stock solution), $0.4 \mathrm{mg} / \mathrm{mL}$ brilliant black, $2.5 \mathrm{mM}$ probenicide, $0.03 \%$ pluronic $\mathrm{F}-127$ ) for $60 \mathrm{~min}$ at $37{ }^{\circ} \mathrm{C}, 5 \% \mathrm{CO}_{2}$. The compounds were dissolved in DMSO with $10 \mathrm{mM}$ stock concentration followed by further dilution with DMSO in 1/3.16 steps. Required test solutions for the assay were obtained by dilution with Tyrode's solution containing $2 \mathrm{mM} \mathrm{CaCl}_{2}$ and $0.05 \%$ BSA. Compounds $(10 \mu \mathrm{L}$ per well) were added and cells were incubated for $10 \mathrm{~min}$ at $37{ }^{\circ} \mathrm{C}, 5 \% \mathrm{CO}_{2}$. Then $20 \mu \mathrm{L}$ of agonist solution (recombinant human CCL2 (PeproTech, 300-04) in Tyrode's solution with 0.05\% BSA) were added. CCL2 was applied at EC50, which was determined in an experiment prior to compound testing (approximately $5 \mathrm{nM}$ ). Fluorescence intensity (excitation: $485 \mathrm{~nm}$, emission: $520 \mathrm{~nm}$ ) was measured for $120 \mathrm{~s}$ in $1.0 \mathrm{~s}$ intervals by a proprietary fluorescence measuring device. IC $_{50}$ values were fitted using a 4 parameter logistic function (Hill function).

\subsubsection{Affinity toward the CCR5}

\section{Chemicals and reagents}

$\left[{ }^{3} \mathrm{H}\right] \mathrm{TAK}-779$ (79.1 Ci/mmol) was purchased from PerkinElmer (custom synthesis).

Cell culture and membrane preparation and $\left[{ }^{3} \mathrm{H}\right] \mathrm{TAK}-779$ binding assay

The CCR5 receptor containing membrane fragments were used according to the instructions of the manufacturer and incubated with various concentrations of the test compound, $2 \mathrm{nM}\left[{ }^{3} \mathrm{H}\right] \mathrm{TAK}-779$ and binding buffer (50 mM HEPES $\mathrm{pH} 7.4,5 \mathrm{mM} \mathrm{MgCl}_{2}, 1 \mathrm{mM} \mathrm{CaCl}_{2}$ and $0.2 \% \mathrm{BSA}$ ) at room temperature. The filter mats were washed with a buffer solution $(50 \mathrm{mM} \mathrm{HEPES} \mathrm{pH}=7.4,500 \mathrm{mM}$ 
$\mathrm{NaCl}$-solution and $0.1 \%$ BSA). The test compound solutions were prepared by dissolving approximately $10 \mu \mathrm{mol}$ (usually 2-4 mg) of the test compound in DMSO so that a $10 \mathrm{mM}$ stock solution was obtained. To obtain the required test solutions for the assay, the DMSO stock solution was diluted with the respective assay buffer. The filter mats were presoaked in $0.5 \%$ aqueous polyethylenimine solution for 2 $\mathrm{h}$ at room temperature before use. All binding experiments were carried out in duplicates in 96-well multiplates. The concentrations given are the final concentrations in the assay. Generally, the assays were performed by addition of $50 \mu \mathrm{L}$ of the respective assay buffer, $50 \mu \mathrm{L}$ test compound solution in various concentrations $\left(10^{-5}, 10^{-6}, 10^{-7}, 10^{-8}, 10^{-9}\right.$ and $\left.10^{-10} \mathrm{~mol} / \mathrm{L}\right), 50 \mu \mathrm{L}$ of corresponding radioligand solution and $50 \mu \mathrm{L}$ of the respective receptor preparation into each well of the multiplate (total volume $200 \mu \mathrm{L}$ ). The receptor preparation was always added last. During the incubation, the multiplates were shaken at a speed of 500-600 rpm at the specified temperature. The assays were terminated after 120 min by rapid filtration using the harvester. During the filtration, each well was washed five times with $300 \mu \mathrm{L}$ of water. Subsequently, the filter mats were dried at $95{ }^{\circ} \mathrm{C}$. The solid scintillator was melted on the dried filter mats at a temperature of $95{ }^{\circ} \mathrm{C}$ for $5 \mathrm{~min}$. After solidifying of the scintillator at room temperature, the trapped radioactivity in the filter mats was measured with the scintillation analyser. Each position on the filter mat corresponding to one well of the multiplate was measured for 5 min with the $\left[{ }^{3} \mathrm{H}\right]$-counting protocol. The overall counting efficiency was $20 \%$.

\section{Data analysis}

All experiments were analysed using the nonlinear regression curve fitting program Prism 3 (GraphPad, San Diego, CA).

\subsubsection{BRET-based cAMP assay at the CCR5 receptor}

Cell culture

The human embryonic kidney (HEK293 T) were cultured in $10 \mathrm{~cm}$ cell culture plates in DMEM/F-12 
medium, supplemented with 10\% fetal bovine serum (FBS), 2 mM L-glutamine, 1\% penicillinstreptomycin and incubated at $37^{\circ} \mathrm{C}$ in a humid atmosphere with $5 \% \mathrm{CO}_{2}$.

\section{cAMP BRET assay}

HEK293T cells were transiently transfected with $1 \mu$ g of the human receptor CCR5 and $2 \mu \mathrm{g}$ of the biosensor CAMYEL, using the TransIT-293 transfection reagent from Mirus 293 (Mirus Bio LLC, Madison, USA). 24 hours after transfection, the cells were seeded in a half-area white 96-wells plate (Grainer-Bio One) containing 20.000 cells/well in $100 \mu \mathrm{L}$ of complete DMEM/F-12 phenol red-free medium. After incubation at $37^{\circ} \mathrm{C}$ in a humid atmosphere with $5 \% \mathrm{CO}_{2}$ overnight, the medium was removed and $30 \mu \mathrm{L}$ of dPBS supplemented with $\mathrm{CaCl}_{2}$ and $\mathrm{MgCl}_{2}$ (Gibco, Life Technologies) were added to each well. After additional hour of incubation at $37^{\circ} \mathrm{C}$ the substrate coelenterazine h (Promega, Madison, USA) was added in each well to a final concentration of $5 \mu \mathrm{M}$ and incubated for 5 min in darkness. Various concentrations of test compounds (prepared in dPBS, $\mathrm{pH} 7.4$, containing 0.2\% BSA, 1\% DMSO, $10 \mu \mathrm{M}$ forskoline, and $0.2 \mathrm{nM}$ of the chemokine CCL4 or $1 \mathrm{nM}$ of the chemokine CCL5) were added to a final volume of $50 \mu \mathrm{L}$ per well and incubated for additional 10 min at room temperature. Bioluminescence was measured with a microplate reader Clariostar (BMG labtech, Ortenberg, Germany). Each concentration was measured in triplicate.

\section{Data analysis}

To characterize the allosteric profile of novel ligands, we applied the ternary complex model of allosterism to analyze the data obtained from the functional assays. The assumptions were that the allosteric modulators do not cause the depression of maximal response or the suppression of the basal activity. The depression of maximal response or the suppression of the basal activity are not accounted for in an ATCM model. Importantly, even if these assumptions do not hold entirely true for all the novel allosteric modulators, this analysis enables a first approximation and a semi-empirical estimate of 
cooperativity. ${ }^{19,20}$ The data from functional studies, where discrete concentrations of agonist CCL4 was used, were fitted to following equations using Prism 7.0:

$$
\begin{aligned}
& K_{\text {app }}=\frac{K_{A}\left(1+\frac{[B]}{K_{B}}\right)}{\left(1+\frac{\alpha \beta[B]}{K_{B}}\right)} \\
& Y=\frac{Y 0\left(1+K_{A}\right)}{\left([c]+K_{\text {app }}\right)}
\end{aligned}
$$

Where $K_{a p p}$ described the occupancy of the orthosteric site, $K_{A}$ was the $E C_{50}$ value of CCL4 or CCL5 for the investigated receptor, [c] the concentration of CCL4 or CCL5 used, [B] the concentration of novel allosteric modulator, $K_{B}$ the equilibrium dissociation constant of modulator binding, and $\alpha \beta$ the ternary complex constant, which denotes cooperativity factor. ${ }^{21}$ In the cAMP assay the $K_{A}$ value for CCL4 was set to $0.2 \mathrm{nM}$. The concentration of the chemokine CCL5 was set to $1 \mathrm{nM}$.

\subsection{Molecular modelling}

All molecular modelling studies were carried out on an Intel Core ${ }^{\mathrm{TM}}$ i7 processor, $8 \mathrm{~GB}$ memory with Windows 10 operating system using MOE (Molecular Operating Environment, 2016.08; Chemical Computing Group Inc., 1010 Sherbooke St. West, Suite \#910, Montreal, QC, Canada, H3A 2R7, 2012.) as the computational software.

For the calculations performed using AM1 of the MOE software package (Molecular Operating Environment (MOE), 2012.10; Chemical Computing Group Inc., 1010 Sherbooke St. West, Suite \#910, Montreal, QC, Canada, H3A 2R7, 2012) the 3D-structures were drawn using Module Builder. The stochastic conformational search was performed under standard conditions. (Method: Stochastic, Rejection Limit 100, Iteration Limit 10000, RMS gradient: 0.005, MM iteration limit 500, RMSD limit: 0.25, Strain Cutoff: 7 kcal/mol, Conformation Limit 10000). 


\section{Acknowledgement}

This work was performed within the framework of the International Research Training Group 'Complex Functional Systems in Chemistry: Design, Synthesis and Applications' in collaboration with the University of Nagoya. Financial support of the IRTG and this project by the Deutsche Forschungsgemeinschaft and the Funding Program for Next Generation World-Leading Researchers from JSPS is gratefully acknowledged. M. M. and N.T. were financially supported by Research Training Group 1962 (GRK1962) of German Research Foundation. N.T. participates in the European COST Action CM1207 (GLISTEN: GPCRLigand Interactions, Structures, and Transmembrane Signaling: a European Research Network). 


\section{References}

1 V. Y. Wu, D. A. Walz, L. E. Mccoy, Prep. Biochem. 7 (1977) 479-493.

2 J. W. Griffith, C. L. Sokol, A. D. Luster, Ann. Rev. Immun. 32 (2014) 659-702.

3 G. Kothandan, C. G. Gadhe, S. J. Cho, PLoS ONE 7 (2012) e32864.

4 Q. Zhao, J. Leuk. Biol. 88 (2010) 41-55.

5. A. Junker, A. Kokornaczyk, A. Strunz, B. Wünsch, Selective and dual targeting of CCR2 and CCR5 receptors - a current overview. In Chemokines: Chemokines and their receptors in drug discovery; editor N. Tschammer, series Top. Med. Chem. 14 (2015, 14) 187-242, Springer International Publishing, Berlin Heidelberg.

6 L. Fantuzzi, P. Borghi, V. Ciolli, G. Pavlakis, F. Belardelli, S. Gessani, Blood 94 (1999) 875-883.

$7 \quad$ R. Horuk, Cytokine Growth Factor Rev. 12 (2001) 313-335.

8 M. Shiraishi, Y. Aramaki, M. Seto, H. Imoto, Y. Nishikawa, N. Kanzaki, M. Okamoto, H. Sawada, O. Nishimura, M. Baba, M. Fujino, J. Med. Chem. 43 (2000) 2049-2063.

9 A. Junker, J. Yamaguchi, K. Itami, B. Wünsch, J. Org. Chem. 78 (2013) 5579-5586.

10 A. Junker, A. K. Kokornaczyk, A. J. M. Zweemer, B. Frehland, D. Schepmann, J. Yamaguchi, K. Itami, A. Faust, S. Hermann, S. Wagner, M. Schafers, M. Koch, C. Weiss, L. H. Heitman, K. Kopka, B. Wünsch, Org. Biomol. Chem. 13 (2015) 2407-2422.

11 A. Junker, D. Schepmann, J. Yamaguchi, K. Itami, A. Faust, K. Kopka, S. Wagner, B. Wünsch, Org. Biomol. Chem. 12 (2014) 177-186.

12 M. Seto, K. Aikawa, N. Miyamoto, Y. Aramaki, N. Kanzaki, K. Takashima, Y. Kuze, Y. Iizawa, M. Baba, M. Shiraishi, J. Med. Chem. 49 (2006) 2037-2048.

13 Z. Zhang, X. Li, T. Song, Y. Zhao, Y. Feng, J. Med. Chem. 55 (2012) 10735-10741.

14 A. K. Kokornaczy, S. Thum, C. Daniliuc, A. Junker, B. Wünsch, Acta Cryst. Sect. 72 (2017) DOI: 10.1515/znb-2017-0030. 
15. L. M. Brown, K. E. Rogers, J. A. McCammon, P. A. Insel, J. Biol. Chem. 289 (2014) 8217-8230.

16. V. Bernat, T. H. Admas, R. Brox, F. W. Heinemann, N. Tschammer, ACS Chem. Biol. 9 (2014) 2664-2677.

17. R. Milanos, T. Brox, G. Frank, R. Poklukar, R. Palmisano, J. Waibel, M. Einsiedel, I. Dürr, O. Ivanović-Burmazović, G. M. Larsen, M. Hjortø, M. Rosenkilde, N. Tschammer, J. Med. Chem. 59 (2016) 2222-2243.

18. A. J. M. Zweemer, I. Nederpelt, H. Vrieling, S. Hafith, M. L. J. Doornbos, H. de Vries, J. Abt, R. Gross, D. Stamos, J. Saunders, M. J. Smit, A. P. Jzerman, L. H. Heitman, Mol. Pharmacol. 84 (2013) 551-561.

19. D. Schmidt, V. Bernat, R. Brox, N. Tschammer, P. Kolb, ACS Chem. Biol. 10 (2015) 715-724.

20. V. Bernat, T. H. Admas, R. Brox, F. W. Heinemann, N. Tschammer, ACS Chem. Biol. 9 (2014) 2664-2677.

21. A. Christopoulos, T. Kenakin, Pharmacol. Rev. 54 (2002) 323-374. 
41

Graphical Abstract
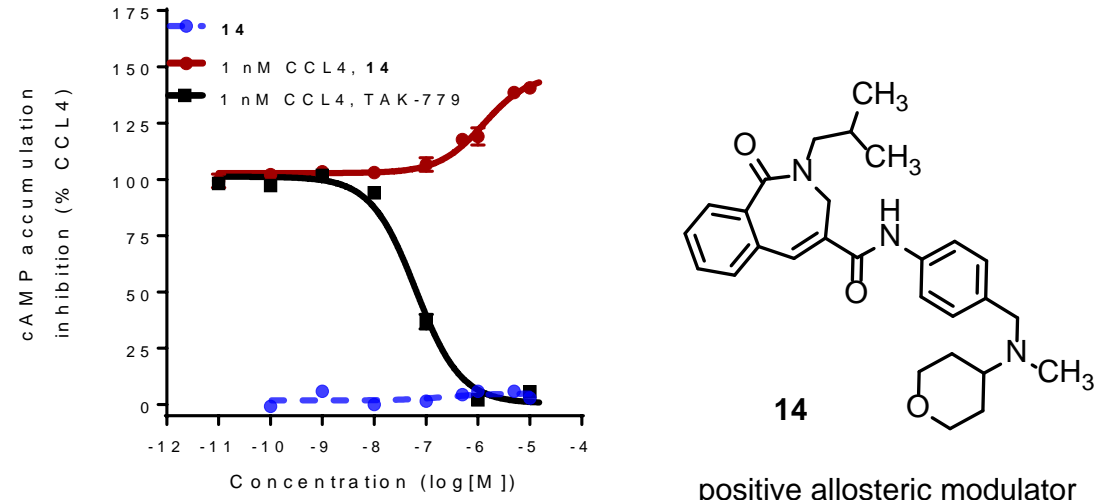

positive allosteric modulator at CCR5 receptor 


\section{Captions of all Figures, Schemes and Tables}

Figure 1: Design of 2-benzazepin-1-ones 3 derived from TAK-779 (1) and TAK-652 (2).

Figure 2: I) Alignment of central core structures of TAK-779 (A, blue) with 7-p-tolyl derivative 26b (B, pink). II) Alignment of central core structures of TAK-652 (C, orange) with 7-p-tolyl derivative 26b (B, pink).

Figure 3: The BRET-based cAMP assay for compounds 14 and TAK-779 (1) with CCL4 at the CCR5 receptor.

Scheme 1: Synthesis of compounds 14 and 16. Reagents and reaction conditions: (a) $1 . \mathrm{NaOCH}_{3}$, $\mathrm{H}_{3} \mathrm{COH}, \mathrm{rt}, 2 \mathrm{~h} ; 2$. $\mathrm{HCl} / \mathrm{Et}_{2} \mathrm{O}, 89 \%$. (b) Monomethyl phthalate (7), $\mathrm{SOCl}_{2}$, pyridine; then addition of 6. $\mathrm{HCl}$, pyridine, $\mathrm{CH}_{2} \mathrm{Cl}_{2}$, rt, 4 h, 64\%. (c) $\mathrm{NaH}$, THF, reflux, $3 \mathrm{~h}, 58 \%$. (d) $\mathrm{NaBH}_{4}, \mathrm{H}_{3} \mathrm{COH}, 0{ }^{\circ} \mathrm{C}, 1 \mathrm{~h}$, 58\%. (e) $\mathrm{H}_{3} \mathrm{CSO}_{2} \mathrm{Cl}, \mathrm{NEt}_{3}, \mathrm{DBU}, \mathrm{CH}_{2} \mathrm{Cl}_{2}, \mathrm{rt}, 12$ h, 76\%. (f) $5 \mathrm{M} \mathrm{NaOH}, \mathrm{H}_{3} \mathrm{COH}$, reflux, 40 min, 100\%. (g) $\mathrm{NEt}_{3}$ (2 equiv.), HATU (1.1 equiv.), THF, rt, 12 h, 14: 48\%, 16: 8\%.

Scheme 2: Synthesis of 7- and 8-(p-tolyl)-2-benzazepine-4-carboxamides 26a,b. Reagents and reaction conditions: (a) $\mathrm{Br}_{2}, \mathrm{NaOH}, \mathrm{H}_{2} \mathrm{O}$, reflux, 72 h, 95\%. (b) TMSCl, $\mathrm{H}_{3} \mathrm{COH}, \mathrm{rt}, 12 \mathrm{~h}, 94 \%$. (c) 1 . $\mathrm{SOCl}_{2}$, pyridine; 2. 6· $\mathrm{HCl}$, pyridine, $\mathrm{CH}_{2} \mathrm{Cl}_{2}$, rt, 4 h, 64\%. (d) $\mathrm{NaH}$, THF, reflux, 3 h, 21a: $36 \%$, 21b: 38\%. (e) $\mathrm{NaBH}_{4}, \mathrm{H}_{3} \mathrm{COH}, 0{ }^{\circ} \mathrm{C}, 1$ h, 22a: 58\%, 22b: 45\%. (f) $\mathrm{H}_{3} \mathrm{CSO}_{2} \mathrm{Cl}, \mathrm{NEt}_{3}, \mathrm{DBU}, \mathrm{CH}_{2} \mathrm{Cl}_{2}, \mathrm{rt}, 12$ h, 23a: 74\%, 23b: 84\%. (g) 4-Methylbenzeneboronic acid, $\mathrm{PdCl}_{2}$ (dppf) (5 mol\%), KOAc, DME, reflux, 12 h, 24a: 50\%, 24b: 58\%. (h) $5 \mathrm{M} \mathrm{NaOH}, \mathrm{H}_{3} \mathrm{COH}$, reflux, 30 min, 97\%. (i) 13, HATU, NEt 3 , THF, rt, 12 h, 26a: 39\%, 26b: 34\%. 
Scheme 3: Synthesis of $\mathrm{NO}_{2}$ derivatives 29 and acetamide 34a. Reagents and reaction conditions: (a) $\mathrm{HNO}_{3}(100 \%), \mathrm{H}_{2} \mathrm{SO}_{4}$ (95 - 97\%), $\mathrm{CH}_{3} \mathrm{NO}_{2}$, rt, 2 h, 83\%. (b) $5 \mathrm{M} \mathrm{NaOH}, \mathrm{H}_{3} \mathrm{COH}$, reflux, 97\%. (c) 13, HATU, NEt 3 , THF, rt, 12 h, 29a: 9\%, 29c: 14\%. (d) Fe, conc. HCl, EtOH, reflux, 2 h, 75\%. (e) $\mathrm{Ac}_{2} \mathrm{O}, \mathrm{NEt}_{3}, \mathrm{CH}_{2} \mathrm{Cl}_{2}, 6$ h, rt, 59\%. (f) $\mathrm{NaOH}, \mathrm{H}_{3} \mathrm{COH}, 10$ min, rt. (g) $\mathrm{Ac}_{2} \mathrm{O}, \mathrm{NEt}_{3}, \mathrm{CH}_{2} \mathrm{Cl}_{2}, 6$ h, rt, $69 \%$. (h) 13, HATU, NEt 3 , THF, rt, 12 h, 47\%.

Scheme 4: Synthesis of sulfonamide 38a: Reagents and reaction conditions: (a) Fe, conc. $\mathrm{HCl}, \mathrm{EtOH}$, reflux, 2 h, 74\%. (b) $\mathrm{CH}_{3} \mathrm{SO}_{2} \mathrm{Cl}$ (1 equiv.), $\mathrm{NEt}_{3}, \mathrm{CH}_{2} \mathrm{Cl}_{2}, 3 \mathrm{~d}$, then 4 x 0.3 equiv. $\mathrm{CH}_{3} \mathrm{SO}_{2} \mathrm{Cl}_{\text {and }} \mathrm{NEt}_{3}$ every 6 h, rt, 91\%. (c) $\mathrm{NaOH}, \mathrm{H}_{3} \mathrm{COH}, 20$ min, rt, 43\%. (d) $\mathrm{LiOH}$ (4 equiv.), $\mathrm{H}_{3} \mathrm{COH}, 3$ h rt, 1 h $50{ }^{\circ} \mathrm{C}$, 53\%. (e) 13, HATU, NEt3, THF, rt, 12 h, 20\%.

Table 1: Receptor affinities and activities at CCR2 and CCR5 receptors.

\section{Under the Table}

[\%] inhibition at a test compound concentration of $1 \mu \mathrm{M}(\mathrm{n}=3)$. n.d. not determined.

[a] Displacement of the radioligand $\left[{ }^{3} \mathrm{H}\right] \mathrm{INCB} 3344$ at a concentration of $1 \mu \mathrm{M}$ of the test compound $(\mathrm{n}=3)$.

[b] Inhibition of $\mathrm{Ca}^{2+}$ mobilization after activation by $5 \mathrm{nM} \mathrm{MCP-1} \mathrm{(n=3).}$

[c] Displacement of the radioligand $\left[{ }^{3} \mathrm{H}\right] \mathrm{TAK}-779$ at a concentration of $1 \mu \mathrm{M}$ of the test compound $(\mathrm{n}=3)$.

[d] Stimulation of cAMP production after inhibition with 0.2 nM CCL4 (n = 3). 